\title{
Effects of Land Use/Cover Change On Atmospheric Humidity in Three Urban Agglomerations in The Yangtze River Economic
}

\section{Baoni Li}

Wuhan University

Lihua Xiong ( $\nabla$ xionglh@whu.edu.cn )

Wuhan University https://orcid.org/0000-0001-6990-2414

Quan Zhang

Wuhan University

Shilei Chen

Wuhan University

Han Yang

Wuhan University

Shuhui Guo

Wuhan University

\section{Research Article}

Keywords: Land use/cover change, Atmospheric humidity, Evapotranspiration, Urban dry island, Remote Sensing

Posted Date: July 23rd, 2021

DOl: https://doi.org/10.21203/rs.3.rs-659431/v1

License: (c) (i) This work is licensed under a Creative Commons Attribution 4.0 International License.

Read Full License 


\section{Effects of land use/cover change on atmospheric humidity in three urban agglomerations in the Yangtze River Economic Belt, China}

Baoni Li ${ }^{\text {a }}$, Lihua Xiong ${ }^{\text {a, }}{ }^{*}$, Quan Zhang ${ }^{\text {a }}$, Shilei Chen ${ }^{\text {a }}$, Han Yang ${ }^{\text {a }}$, and Shuhui Guo ${ }^{\text {a }}$

a State Key Laboratory of Water Resources and Hydropower Engineering Science, Wuhan University, Wuhan 430072, P. R. China

E-mail addresses:

B.Li(baonili@whu.edu.cn)

L.Xiong (xionglh@whu.edu.cn)

Q.Zhang(quan.zhang@whu.edu.cn)

S.Chen (chenslwater@126.com)

H.Yang (hanyang1994@whu.edu.cn)

S.Guo (shguol@whu.edu.cn)

* Corresponding author:

Lihua Xiong

State Key Laboratory of Water Resources and Hydropower Engineering Science

Wuhan University, Wuhan 430072, P. R. China

E-mail:xionglh@whu.edu.cn

Telephone: $+86-13871078660$ 


\section{ABSTRACT}

2 Land use/cover change (LUCC) affects regional climate not only through its direct 3 changes of land surface properties, but also through its further modifications of 4 land-atmosphere interactions. Urban land expansion is a typical case of LUCC in

5 highly populated areas, and has been widely discussed about its impacts on regional air 6 temperature, notably known as urban heat island (UHI) effects. Besides air temperature, 7 atmospheric humidity, as another key variable in hydrometeorology and climate, would 8 be inevitably affected by LUCC as well. However, the impacts of LUCC on 9 atmospheric humidity seem to have not been investigated as much as on temperature. 10 We examined atmospheric humidity changes by trend analyses of humidity indicators in three representative urban agglomerations in the Yangtze River Economic Belt 12 (YREB), China during 1965-2017, and found the evident urban dry island (UDI) effects which are characterized by significant humidity decrease and vapor pressure deficit increase. In different urban cores, the severity levels of UDI are different. Furthermore, strong positive correlations between humidity and evapotranspiration, and between evapotranspiration and leaf area were detected during 2001-2017 when cities entered the accelerated stage of land expansion, indicating that LUCC affects regional climate through an ecohydrological way. We speculated that the UDI effect will not appear until urban land expands to a certain scale. Besides, the UHI effect emerged in the early stage of urban expansion, about 5 years earlier than the UDI effect, and has not performed prominently in recent years. This implies that urbanization-induced LUCC may exert a larger influence on UDI than on UHI in the current later period of urban expansion.

Keywords: Land use/cover change; Atmospheric humidity; Evapotranspiration; Urban dry island; Remote Sensing 


\section{Introduction}

Land use/cover change (LUCC) affects local and regional climate not only through its direct changes of land surface radiative, biophysical and aerodynamic properties such as albedo and roughness, but through further modifications of land-atmosphere interactions which incorporate the surface energy budget, water cycle and carbon cycle (Betts et al., 1996; Boisier et al., 2012; Foley et al., 2005; Ma et al., 2019; Rigden and Li, 2017; Pielke et al., 2011). Urbanization as one of most typical cases of LUCC in highly populated areas, is characterized by the rise of impervious surfaces at the cost of vegetated and evaporating soil surfaces, which triggers a series of consequences on regional climate (Clinton and Gong, 2013; Li et al., 2020; Song et al., 2018; Zhou et al., 2016). The most well recognized and discussed effect is urban heat island (UHI) which depicts warmer urban areas than its surroundings, and it is generally attributed to changes in surface radiative heating and surface energy redistribution (Arnfield, 2003; Li et al., 2019; Logan et al., 2020; Oke, 1982; Taha, 1997; Zhou et al., 2014). Closely accompanying UHI, another less discussed but equally important urbanization effect on regional climate is urban dry island (UDI) which describes that urban areas have lower atmospheric humidity than its surroundings (Akinbode et al., 2008; Landsberg and Maisel, 1972; Lokoshchenko, 2017).

Researches have already displayed different consequences of UDI. Numerical simulations and statistical analysis found that UDI could mitigate urbanization effect on warming through compensating for the impact of anthropogenic aerosols on downward longwave radiation, because UDI could decrease urban cloud cover due to more mixing of water vapor in the boundary layer and less convective available potential energy (Du et al., 2019; Zhang et al., 2009). Furthermore, UDI could improve human thermal comfort to some extent under UHI, because perceived heat stress was stronger when relative humidity was higher under given temperature and people would tend to be more sensitive to changes in humidity than to changes in temperature at high temperatures (Barradas, 1991; Gaffen and Ross, 1999; Hondula et al., 2017; Luo and 
Lau, 2018). However, UDI could also slow down the water vapor to reach its saturation and extend the life time of dust, smoke and particulate matters suspending in the air, making it difficult for the haze particles to transform into fog drops and subsequently leading to lower horizontal visibility (Ding and Liu, 2014; Gultepe et al., 2007). A higher water demand for irrigation of urban ecosystem would also emerge due to the increase of potential evapotranspiration caused by drying urban boundary layer atmosphere (Yang et al., 2017). Therefore, it is of great societal concerns to explore both the temporal-spatial patterns of UDI and its drivers behind so as to understand more aspects of urbanization effects on regional climate.

Previous literatures related to UDI mainly focused on the description of the phenomenon, its temporal and spatial patterns and superficial causes. Based on the findings that vapor content had diurnal and seasonal cycles, lower humidity of urban areas than that of rural areas during daytime was attributed to temperature rise and ET reduction in cities while nighttime opposite phenomenon was attributed to enhanced dewfall in the countryside and higher temperature of night urban air which had the potential to contain more water vapor (Hage, 1975; Landsberg and Maisel, 1972; Moriwaki et al., 2013). Generally, humidity differences between urban and rural areas were negative during the summer, while positive ones were found in winter and were related to urban combustion sources of water vapor, urban snowmelt on occasions when rural temperatures were below freezing and the seasonal features of the wind (Ackerman, 1987; Moriwaki et al., 2013). Spatial patterns of UDI within cities were related to urban topography and geometry, vegetation cover of park and garden areas, and the frequency and intensity of the wind (Cuadrat et al., 2015; Yang et al., 2017).

Despite the identification of UDI characteristics, only very few researches have thought of it as a consequence of urbanization-induced LUCC in addition to other kinds of human activities and investigated the corresponding underlying mechanisms (Boisier et al., 2012; Luo and Lau, 2019; Pielke et al., 2011). Urban land expansion carries on majorly at the expense of rural lands used for agriculture and forestry, which 
leads to lower rates of evapotranspiration (ET; Boggs and Sun, 2011; Sun and Lockaby, 2012). Generally recognized as a major moisture source of atmospheric humidity as well as a major contributor to UDI, ET is a key hydrometeorological variable uniquely linking the energy cycle and the water cycle and found to be controlled by both climatic factors and LUCC (Fisher et al., 2017; Li et al., 2017; Tan et al., 2014; Odongo et al., 2019). Thus, it is rational to relate LUCC (i.e., leaf area index [LAI]) to the coupling of hydrological (i.e., ET) and meteorological (i.e., air temperature and humidity) processes, in order to better understand UDI in the interactions between ecohydrological processes and urban climate feedbacks (Bronstert et al., 2002; Hao et al., 2018; Sun et al., 2011).

After the initial urban transition stage between 1950 and 1980, China is now in its late period of the accelerated stage between 1980 and 2030 (Farrell and Westlund, 2018). The urban built-up areas of the nation have gained from $6720 \mathrm{~km}^{2}$ in 1981 to $56075.9 \mathrm{~km}^{2}$ in 2018 , with an average annual growth rate of $5.902 \%$ (Ministry of Housing and Urban-Rural Development of the People's Republic of China, 2020). Relying on the abundant natural resources of the Yangtze River Basin, the Yangtze River Economic Belt (YREB), a key zone supporting the sustained growth of economy of the nation, takes the lead in the urbanization development. Meanwhile due to differences in natural resources and economic development, there are obvious temporal and spatial differences in the urbanization process of urban agglomerations in the upper, middle and lower reaches of the Yangtze River. Therefore, selecting areas with obvious but varying degrees of urban expansion processes for comparative research and analysis can reflect the differences in the impacts of urbanization processes on regional climate changes to some extent.

In this study, three representative urban agglomerations with different levels of urbanization along the Yangtze River was examined for their atmospheric humidity changes and trends, so as to detect the potential effects of rapid urban expansion on local and regional climate, specifically UDI development. Correlation analyses was 
111 performed between the pairs of atmospheric humidity indicators and ET, atmospheric

112 humidity indicators and temperature and ET and LAI, intending to explain the

113 mechanisms how urbanization affects local and regional climate through

114 ecohydrological processes. Our results may spark insights into future urban planning

115 and landscape design in mitigating climate change and maintain sustainable

116 development, and more quantitative estimations of urban expansion effects on local

117 and regional drying trends are needed especially when urbanization development

118 reaches to a certain scale.

\section{Data and Methods}

\subsection{Study Area}

The study areas include three national-level urban agglomerations in the Yangtze River Economic Belt (YREB; Fig. 1): the Yangtze River Delta urban agglomeration (YRDUA), the midstream urban agglomeration (MUA) and the upstream urban agglomeration (UUA). The boundaries of the three urban agglomerations as well as urban cores are identified by administrative divisions from National Development and Reform Commission of China. Sites located in areas with much less built-up lands are selected as representative rural sites. More basic information of the study areas is shown in Table 1.

The YREB is located in the central and southern part of the nation and extends from Shanghai in the east to Yunnan in the west, covering 11 provinces with an area of approximately 2.05 million $\mathrm{km}^{2}$. Located in the subtropical monsoon region and with a relatively low latitude, the YREB has a relatively large amount of solar radiation. The northerly wind prevails in winter and the southerly wind prevails in summer. In addition to these common geographical and climatic conditions, there also lies some differences among the three urban agglomerations. YRDUA is located in the lower 
reaches of the Yangtze River, bordering the Yellow Sea and the East China Sea, at the intersection of the river and the sea. The Taihu Plain is the main body of YRDUA. MUA connects the east to the west, the south to the north and includes the Jianghan Plain, the Dongting Lake Plain and the Poyang Lake Plain. UUA is located in the Sichuan Basin. It is divided into Chengdu Plain, central Sichuan hills and parallel ridge valleys in eastern Sichuan. The mountainous area around the enclosed basin is relatively low in the southeast, which is favorable for the entry of water vapor. The relatively high mountainous area in the northwest is not conducive to the loss of water vapor, resulting in high air humidity, rainy and foggy weather, less sunshine and low wind speed.

In the early 1990s, YRDUA was well ahead in the process of urbanization after Pudong Development and Opening-up started. Then UUA and MUA began to emerge when "Four Alongs" Open Development Strategy was proposed. The proposal and implementation of the West China Development in 1999 and the Central Rising Strategy in 2006 led to rapid growth of UUA and MUA, respectively. In 2014, the "Guiding Opinions on Promoting the Development of the YREB by Relying on Golden Waterways" and the "Plan of the Comprehensive Three-Dimensional Transportation Corridor of the YREB (2014-2020)" was released to promote the synergistic development of the three urban agglomerations.

$<$ Fig. $2>$

Urban built-up areas reflected by impervious surfaces show obvious urban land expansion around core cities in all three urban agglomerations, especially in YRDUA (Fig. 2a, 2c and 2e). At the beginning of economic reform in China in 1978, the percentage of impervious surface in YRD, MUA and UUA is $0.641 \%, 0.055 \%$ and $0.048 \%$, respectively, while by the time of 2017 , the number changes into $11.768 \%$, $2.413 \%$ and $1.956 \%$, respectively (Fig. 2b, 2d, and 2f). Urban impervious surface in YRD first increased at a lower rate of $0.10 \%$ every year from 1978 to 2000 , and then surged at the speed of $0.55 \%$ every year after 2000 . Neither MUA nor UUA showed 
obvious changes in impervious surface from 1978 to 2000, while they both began to expand built-up areas after 2000, at not very high rates similar to the first increasing stage of YRDUA. These differences in urban expansion processes imply that urbanization effects on local and regional climate in YRDUA probably have begun to take form, while MUA and UUA have just experienced the initial subtle impacts of urbanization. Therefore, it is rational to compare changes of local climate conditions of these three urban agglomerations in order to advance understanding of effects of different levels of urbanization.

\subsection{Regional ET, LAI and Impervious surface area}

The improved MOD16A2V006 Moderate Resolution Imaging Spectroradiometer (MODIS) dataset, providing global actual evapotranspiration (ET) estimates with a resolution of 8-day and 500-m from 2001 to 2017 (Running et al., 2017), was acquired to explore ET and its changes of urban agglomerations. Leaf area index ( LAI ) used to assess vegetation cover changes was acquired from MOD15A2HV006 dataset also with a resolution of 8-day and 500-m from 2001 to 2017 (Myneni, et al., 2015). These two MODIS products were then batch processed by MODIS Reprojection Tool and ArcGIS to obtain annual mean LAI and annual ET of the study area. The 40-year (1978-2017) continuous and consistent impervious surface distribution data in 30-m resolution in China (Gong et al., 2019) was employed to reflect urban built-up land expansion scales of the study area.

\subsection{Climate Data}

The daily meteorological data was acquired from 187 standard weather stations across YRD, MUA, and UUA (59, 86 and 42, respectively) for the period of 1965-2017. Obtained from the China Meteorological Administration, the meteorological data which included daily mean relatively humidity ( $R H, \%$ ), atmospheric pressure (pres, $\mathrm{kPa}$ ), and daily maximum and minimum near-surface air 
193 (i.e., actual vapor pressure $\left(e_{a}\right)$, specific humidity $(q)$ and vapor pressure deficit $194(V P D))$ through a series of empirical formulas. After calculation at the station level, 195 Ordinary Kriging Interpolation Algorithm (Matheron, 1963) was applied to interpolate the stational meteorological data into grid data with a 500-m spatial resolution in accordance to the resolution of MODIS-derived datasets, so as to further investigate regional climate changes.

\subsection{Humidity Indicators}

A number of humidity variables can be employed to reflect atmospheric humidity considering different purposes (Song et al., 2012). In order to investigate both water vapor content and the moist degree of the atmosphere, herein four humidity indicators were examined: $R H, q, e_{a}$ and $V P D$. Saturation vapor pressure indicating the ability of the air to hold moisture, can be calculated from the air temperature (Allen et al., 1998):

$$
e^{o}(T)=0.6108 \exp \left[\frac{17.27 T}{T+237.3}\right]
$$

210 minimum air temperature $\left(T_{\min },{ }^{\circ} \mathrm{C}\right)$ :

$$
e_{s}=\frac{e^{o}\left(T_{\max }\right)+e^{o}\left(T_{\min }\right)}{2}
$$

Actual vapor pressure $\left(e_{a}, \mathrm{kPa}\right)$ is calculated as the mean saturation vapor pressure $\left(e_{s}, \mathrm{kPa}\right)$ multiplied by measured daily mean relative humidity $(R H, \%)$ : 
Vapor pressure deficit $(V P D, \mathrm{kPa})$ representing the atmospheric moisture demand is defined as the difference between $e_{s}$ and $e_{a}$ :

$$
V P D=e_{s}-e_{a}
$$

Specific humidity $(q, \mathrm{~g} / \mathrm{g})$ is the ratio of the mass of water vapor to the total mass of the moist air parcel:

$$
q=\frac{0.622 e_{a}}{\text { pres }-0.378 e_{a}}
$$

where pres is the atmospheric pressure $(\mathrm{kPa})$.

\subsection{Trend and Change Point analyses}

First the simple linear regression analysis was employed to detect the trends of atmospheric humidity indicators at the pixel level. The slope of the linear fitted lines represents the direction and extent of the trend. Then the significance of the trend was evaluated by the non-parametric Mann-Kendall (MK) test (Kendall, 1975; Mann, 1945). The MK test is based on the test statistic $S$ defined as:

$$
S=\sum_{i=1}^{n-1} \sum_{j=i+1}^{n} \operatorname{sgn}\left(x_{j}-x_{i}\right)
$$

where $x_{i}$ is the sequential data value at time $i, n$ is the length of the dataset, and

$$
\operatorname{sgn}\left(x_{j}-x_{i}\right)=\left\{\begin{array}{rc}
1 & x_{j}>x_{i} \\
0 & x_{j}=x_{i} \\
-1 & x_{j}<x_{i}
\end{array}\right.
$$

When $n$ is larger than 10 , the statistic $S$ is approximately normally distributed with the mean and variance as:

$$
E(S)=0
$$




$$
\operatorname{Var}(S)=\frac{1}{18}\left[n(n-1)(2 n+5)-\sum_{k=1}^{m} t_{k}\left(t_{k}-1\right)\left(2 t_{k}+5\right)\right]
$$

where $m$ is number of tied groups and $t_{k}$ is the number of records in the $k$ th tied group. The standardized test statistic $Z$ is calculated as:

$$
Z=\left\{\begin{array}{cc}
\frac{(\mathrm{S}-1)}{\sqrt{\operatorname{Var}(S)}} & \mathrm{S}>0 \\
0 & \mathrm{~S}=0 \\
\frac{(\mathrm{S}+1)}{\sqrt{\operatorname{Var}(S)}} & \mathrm{S}<0
\end{array}\right.
$$

The null hypothesis that there is no trend would be rejected if the absolute value of $Z$ is larger than $Z_{1-\alpha / 2}$, where $Z_{1-\alpha / 2}$ is the upper $\alpha / 2$ quantile of the standard normal distribution.

A divisive hierarchical estimation algorithm for multiple change point analysis was employed at the station level to identify the significant humidity and air temperature change points of core cities. This method is based on Euclidean distance between the sample observations. Let $x_{1}, x_{2}, \cdots, x_{n} \in x^{d}$ be an independent sequence of observations, where $x_{n}$ is the independent and integrated (iid) observations in time $n$. Then there is a single hypothesized change point location $\tau$, in which $x_{1}, \cdots, x_{\tau} \sim F_{1}$ and $x_{\tau+1}, \cdots, x_{n} \sim F_{2}$. The homogeneity in distributions is tested with the null hypothesis of $F_{1}=F_{2}$. Further this approach is extended to a nonparametric technique named E-Divisive that can simultaneously identify both number and location of change points of a sequence of multivariate observations without any prior assumption (Matteson and James, 2014; James and Matteson, 2014). The statistical significance of the E-Divisive is determined by a permutation test under the null hypothesis of no additional change point. 


\subsection{Correlation analysis}

The Pearson's correlation analysis (Pearson, 1895) was performed for key variables at the pixel level between the pairs of $R H$ and ET, $q$ and ET, $e_{a}$ and ET, $V P D$ and ET, RH and air temperature (TEM), ET and LAI. The Pearson's Correlation Coefficient $(r)$ is calculated as:

$$
r=\frac{1}{n} \sum_{i=1}^{n}\left[\left(\frac{x_{i}-\bar{x}}{S_{x}}\right)\left(\frac{y_{i}-\bar{y}}{S_{y}}\right)\right]
$$

where $n$ is the size of time series, $x_{i}$ and $y_{i}$ are the observed values, $\bar{x}$ and $\bar{y}$ are mean value of observed values, $S_{x}$ and $S_{y}$ are standard deviations. The significance of $r$ is determined by $t$-test. According to both $r$ and the significance level, there are three types of correlation in this study: "Significantly positive correlation" with $p<0.1$, "Significantly negative correlation" with $p<0.1$, and "Nonsignificant correlation" with $p>0.1$.

\section{Results and Discussion}

First the observed annual mean $R H$ of core cities and their surrounding rural areas at the station level were explored to find out if there were apparent changes of atmospheric humidity. Then more humidity indicators were calculated and the stational meteorological data were interpolated into grid data so as to check the regional patterns of humidity changes. At last, the explanation and underlying mechanisms for humidity changes were examined and discussed.

\subsection{The Appearance of UDI 5 years after UHI}

The station level data of annual mean $R H$ and air temperature (TEM ; Fig. 3, 4 and 5) of core cities and rural areas in the three urban agglomerations (Fig. 1b-d) was detected by non-parametric multiple change point analysis. The results suggest that 
there was a common significant change point of TEM with $p<0.05$ at around

278

279

280

281

282

283 1995 in almost all stations, no matter urban or rural ones. Before the change point, TEM significantly increased at a high rate, and after 1995, TEM begun to fluctuate without obvious rise or fall. These results proved the warming trend and the time period of significant TEM rise, i.e., before 2000, which suggests that TEM rise happened before rapid urbanization as discovered in Fig. 2. Meanwhile, relatively small but almost simultaneous warming of rural areas compared to core cities further implies that urbanization may not be the major contributor to the appeared UHI effect, consistent with the former researches (Sun et al., 2016; Zhou et al., 2014).

The common significant change point of $R H$ in core cities with $p<0.05$ was at around 2000, while almost no significant change point was found in the rural areas. This indicates that core cities went through significant $R H$ decline at different levels after 2000 when urban expansion came into the accelerated stage, while $R H$ in rural areas did not display obvious changes. Since significant changes in TEM precede $R H$, the UHI effect occurred generally previous to the UDI effect for about 5 years. Considering that the rapid expansion of urban impervious surface took place only after 2000 when $R H$ begun to decrease while TEM remained stable, it is fair to infer that the impact of LUCC on UDI is superior to that on UHI. Urban lands with more impervious surface instead of vegetation cover, simultaneously working with other factors such as anthropogenic aerosols and greenhouse gases, might reduce surface radiative heating, which is first and predominantly balanced by reduction in the latent heat flux (i.e., evapotranspiration) and then the sensible heat flux (Dhara, 2020; Liepert et al., 2004; Miller et al., 2004; Taha, 1997; Wild et al., 2004). Thus, urbanization-induced LUCC may have a larger influence on evapotranspiration and thereby on the atmospheric humidity above the ground, and then the UDI effect appears.

$<$ Fig. 3 $>$

$<$ Fig. 4> 


\subsection{Regional UDI Patterns}

The regional $R H$ trend of YRDUA suggests that the whole region has experienced decreasing $R H$ at different levels during 1965-2017 (Fig. 6a). Regional mean annual $R H$ decreased at the rate of $0.980 \%$ per decade, while the drying trends were most significant in the central and eastern areas with a maximum decreasing speed of $2.396 \%$ per decade. The decreasing trends of $R H$ in the northern and western areas were relatively smaller. The regional disparities of $R H$ trend followed a quite similar spatial distribution pattern of impervious surfaces (Fig. 2a), implying that this phenomenon may be an effect of urban expansion. The station level data (Fig. 3) detected by non-parametric multiple change point analysis further suggests that there was a common significant change point of $R H$ with $p<0.05$ at around 2003 in all three core cities (i.e., Nanjing, Shanghai, and Hangzhou), which means that $R H$ started to decrease sharply after 2003 while just fluctuated mildly before 2003 . Meanwhile $R H$ in areas with lagged urbanization almost stayed unchanged with modest fluctuation except Sheyang where significant but relatively small $R H$ decrease of $0.340 \%$ per decade was found (Table 2). The trends of the other three humidity indicators (Fig. 6b-d) once more confirmed the drying climate and its regional changing disparities in the region (maximum rates of $-0.110 \mathrm{~g} / \mathrm{kg}$ per decade, $-0.179 \mathrm{hPa}$ per decade and $0.720 \mathrm{hPa}$ per decade for $q, e_{a}$ and $V P D$, respectively). More noticeably, associated with urban expansion and connectivity development, a dry island cluster instead of isolated dry islands has formed, mainly centered on core mega-cities, agreeing with the former studies (Hao et al., 2018; Luo and Lau,2019).

$<$ Fig. 6>

$<$ Table 2>

The regional $R H$ trend of MUA shows that most areas have undergone different levels of $R H$ decline except the western fringe, during 1965-2017 (Fig. 7a). Regional 
mean annual $R H$ decreased at the rate of $0.646 \%$ per decade. The most obvious decreasing rate of $R H$ was found in the west-central and eastern Nanchang areas, and reached as high as $1.977 \%$ per decade. The spatial distribution pattern of $R H$ trend was related but not completely similar to the distribution of impervious surfaces (Fig. 2c). The station level data (Fig. 4) further shows that $R H$ in Wuhan dropped sharply after 1995 and then started to rebound after 2004, back to almost the levels of 1990s after 2010. $R H$ in the other two core cities, i.e. Nanchang and Changsha, both decreased obviously at about 2005, and then has rebounded to varying degrees in recent years. $R H$ in the surrounding rural areas, i.e., Nanzhang, Lushan and Nanyue, remained almost unchanged for all the years and no significant change point was detected (Fig. 4, Table 2). The regional variation of trends of the other three humidity indicators (Fig. 7b-d) were slightly different but generally consistent with that of $R H$. The maximum changing rates was $-0.139 \mathrm{~g} / \mathrm{kg}$ per decade, $-0.248 \mathrm{hPa}$ per decade and $0.588 \mathrm{hPa}$ per decade for $q, e_{a}$ and $V P D$, respectively.

\section{$<$ Fig. 7>}

The regional $R H$ trend of UUA shows that areas with intensive human activities has gone through different levels of $R H$ decline during 1965-2017 (Fig. 8a). Regional mean annual $R H$ decreased at the rate of $0.654 \%$ per decade, and the drying trend was most obvious in northern Chengdu and its surrounding areas with a maximum decreasing speed of $1.982 \%$ per decade. The station level data (Fig. 5) further shows that after 2001, $R H$ in Chengdu first declined obviously, and then has rebounded a little in recent years, while $R H$ in Chongqing only displayed decreasing trend after 2010. $R H$ of Nanbu and Naxi in the surrounding areas with lagged urbanization almost remained unchanged or displayed unobvious downward fluctuation (Fig. 5, Table 2). The regional variation of trends of the other three humidity indicators (Fig. 8b-d) were slightly different but generally consistent with that of $R H$. The maximum changing rates was $-0.125 \mathrm{~g} / \mathrm{kg}$ per decade, $-0.211 \mathrm{hPa}$ per decade and $0.582 \mathrm{hPa}$ per decade for $q, e_{a}$ and $V P D$, respectively. 
$<$ Fig. $8>$

Abovementioned regional and station levels analyses of atmospheric humidity indicators suggest that the distribution of decreasing trends have shown quite similarity to the expansion of urban impervious surface, and $R H$ in core cities in all three urban agglomerations generally decreased sharply in succession after 2000 , corresponding to the accelerated urban expansion process. Thus, focusing on the cause of urban drying climate after 2000 helps advancing understanding in the effects of urbanization on local and regional climate.

\subsection{Enhanced UDI Explained by ET Decline}

$E T$ is the main source of water vapor in the air, and its changes are closely related to the changes of atmospheric humidity above the ground (Ackerman, 1987; Moriwaki et al., 2013). Through satellite remote sensing data (Fig. 9), it can be found that ET in most areas of YRDUA decreased significantly from 2001 to 2017, especially in the central and eastern areas where human activities were most intensive. Northwestern areas of the region first experienced ET decline from 2001 to 2009, and then showed significant ET rise from 2009 to 2017 compensating for the lost in the first stage to some extent. ET in the southern areas kept mounting at various speed for the whole period. In MUA, the northern part first undergone ET decline, and then displayed significant ET rise after 2011. Southern areas of the region showed a relatively sustained decline of ET especially at human gathering areas. In UUA, ET in the northwestern areas first decreased overall after 2001, and then increased quite a lot after 2009 except areas under intensive human activities. The eastern parallel ridge valleys of the region first experienced $E T$ decline and then $E T$ has recovered significantly since 2009 .

$<$ Fig. 9>

Further analysis of the correlations between humidity indicators and ET in 386 YRDUA suggests that in the central urban core areas where human activities were 
intensive, $R H, q$ and $e_{a}$ all have a significant positive correlation with ET ( $p$ $<0.1$; Fig. 10a-c), while $V P D$ and $E T$ have a significant negative correlation ( $p$ $<0.1$; Fig. 10d), which indicates that the general ET decline greatly explains the decreasing trend of atmospheric humidity in Nanjing, Shanghai, Hangzhou and their surroundings.

$<$ Fig. 10>

The correlation analysis between humidity indicators and ET in MUA shows that in the northern and eastern areas, $R H, q$ and $e_{a}$ all have a significant positive correlation with ET $(p<0.1$; Fig. 11a-c), while VPD has a significant negative correlation with ET $(p<0.1$; Fig. 11d). In the central and south-central areas, only $q$ and $e_{a}$ have a significant positive correlation with ET $(p<0.1$; Fig. 11b-c), and no significant correlation is found between $R H / V P D$ and $E T$. Thus, the decreasing trend of humidity in Wuhan, Nanchang and their surroundings can be well explained by ET declines while the small decrease of humidity in Changsha does not correlated well to ET declines. The distribution of the Dongting lake may take a part in the explanation for relatively small changes of atmospheric humidity in Changsha and its surrounding areas. The weak UDI in Wuhan and its surrounding areas may be related to the increase of greening and water areas in recent years.

$<$ Fig. 11>

Similar correlation analysis performed between humidity indicators and ET in UUA has found that $R H$ has a significant negative correlation with $E T \quad(p<0.1)$ in the eastern parallel ridge valleys and a significant positive correlation with ET ( $p$ $<0.1$; Fig. 12a) in the northwestern Chengdu areas. $q$ and $e_{a}$ both have a significant positive correlation with ET $(p<0.1)$ in the south-central and northwestern areas and a negative correlation with ET $(p<0.1$; Fig. $12 \mathrm{~b}-\mathrm{c})$ in the east-central areas. VPD 
412 has a significant positive correlation with ET $(p<0.1$; Fig. 12d $)$ in the eastern 413 parallel ridge valleys and the circumference of the Sichuan Basin. Therefore, the 414 decreasing trend of humidity in northwestern Chengdu Plain and Chongqing central 415 areas can be explained by ET declines to some extent. The atmospheric humidity changes in the eastern areas may be strongly affected by the topography of the eastern parallel ridge valley, which has a great influence on the atmospheric circulation process. Scatterplots of the humidity indicators versus ET were shown in Fig. 13.

Usually air temperature exerts a tremendous influence on atmospheric humidity by altering the ability of air parcels to hold water vapor (Allen and Ingram, 2002; Landsberg and Maisel, 1972; Moriwaki et al., 2013). The station level data (Fig. 3, 4, 5) detected by non-parametric multiple change point analysis in three urban agglomerations shows that there was a common significant change point of TEM with $p<0.05$ at around 1997 in all urban and rural stations except Nanbu in UUA, which indicates that TEM displayed obvious rise before 2000 and then reached a relatively stable state no matter in urban or rural areas, corresponding to the backdrop of global warming (Liepert et al., 2004; Wild et al., 2004). Thus, the small fluctuations of TEM after 2000 may not be able to explain neither the humidity decline at the same period nor the urban-rural differences in humidity trends. Thus, the enhanced UDI may not be explained by changes of air temperature. A further correlation analysis confirmed that no significant correlation between $R H$ and TEM was found in urban core areas (Fig. 14). it can be seen that LAI decreased in almost all areas in YRDUA except the southern 
439 part from 2001 to 2017 . The decrease was more obvious from 2001 to 2009 , and then 440 the decreasing rate visibly slowed down from 2009 to 2017 . Changes of LAI in 441 MUA were more obvious in the northern, southwestern and southeastern areas where 442 human activities were intensive, with different speed of decline. LAI of almost all areas in UUA showed decline from 2001 to 2017, except the circumference of the

444 Sichuan Basin. Overall, the LAI decrease in the YRDUA region was the most significant, and the UUA region had the smallest decrease, which coincided with the different levels of rapid urban expansion process of the three urban agglomerations after 2000. What's more, almost all areas of the three urban agglomerations had a significant positive correlation between ET and LAI $(p<0.1$; Fig. 16). This strongly suggests that LUCC has greatly changed the vegetation coverage, thereby affecting the corresponding evapotranspiration process and the water vapor content in the air, i.e., the atmospheric humidity.

\section{Conclusions}

In this study, a linear regression method was employed to detect the trends of humidity indicators in three urban agglomerations with different levels of urbanization in the YREB at the pixel level during 1965-2017, and the significance of the trend was tested by the nonparametric Mann-Kendall test. We found different degrees of urban dry island (UDI) effects in the three urban agglomerations, which was featured by humidity decrease and vapor pressure deficit increase of varying severity. Among all, the Yangtze River Delta urban agglomeration (YRDUA) with the fastest urbanization process and the largest percentage of urban impervious surface $(0.641 \%$ in 1978 and $11.768 \%$ in 2017) had the most obvious UDI effect, with the maximum changing speeds of relative humidity and vapor pressure deficit reaching $-2.396 \%$ per decade and $0.720 \mathrm{hPa}$ per decade. The midstream urban agglomeration (MUA) and the upstream urban agglomeration (UUA) with relatively few but close urban impervious 
surface $(2.413 \%$ and $1.956 \%$ in 2017$)$ had weaker UDI effects than YRDUA, with the maximum changing rates of $-1.977 \%$ per decade and $-1.982 \%$ per decade of relative humidity, and $0.588 \mathrm{hPa}$ per decade and $0.582 \mathrm{hPa}$ per decade of vapor pressure deficit for MUA and UUA.

Further a multiple change point analysis performed at the core cities and their surrounding rural stations suggested that there was a general change point of relative humidity at about 2000 in all three urban agglomerations, corresponding to the accelerated urban expansion process after 2000. The correlation analyses were performed between atmospheric humidity indicators and $E T$, between atmospheric humidity indicators and air temperature, and between ET and LAI to explore the mechanism of possible LUCC effects on local and regional atmospheric humidity. We found that the urban expansion with rapidly growing impervious surface at the expense of vegetation cover had a strong influence on regional atmospheric humidity. Specifically, atmospheric humidity decreased due to ET decline as a result of LAI decrease, indicating that urban expansion could affect regional climate through modifying the ET part in the ecohydrological process.

What's more, it was also found that core cities tended to form dry land clusters instead of an isolated dry island due to the urban expansion and connectivity. We speculate that the UDI effect will not appear until urbanization development reaches to a certain scale when a large quantity of vegetation cover is replaced by impervious surface, and the urbanization-induced LUCC may exert a larger influence on UDI than on UHI. Thus, the UDI effect may be more prominent than the UHI effect in the later period of accelerated urban expansion. Considering that future cities will continue to develop into urban agglomerations, the standing out impacts of urbanization on local and regional climate, especially on atmospheric humidity, should attract wider attention so as to mitigate climate change and maintain sustainable development.

\section{Declarations}

Funding: This study is financially supported jointly by the National Natural Science 
Availability of data and material: All datasets used in this study are accessible through the website links given in the article.

Conflicts of interest: None.

\section{References}

501

Ackerman B (1987) Climatology of Chicago Area Urban-Rural Differences in Humidity. Journal of https://doi.org/10.1175/1520-0450(1987)026<0427:COCAUR >2.0.CO;2

Arnfield AJ (2003) Two decades of urban climate research: a review of turbulence, exchanges of energy and water, and the urban heat island. Internatinal Journal of Climatology 23:1-26. https:// doi:10.1002/joc. 859

Akinbode OM, Eludoyin AO, Fashae OA (2008) Temperature and relative humidity distributions in a medium-size administrative town in southwest Nigeria. Journal of Environmental Management 87:95-105. https://doi.org/10.1016/j.jenvman.2007.01.018

Allen M, Ingram W (2002) Constraints on future changes in climate and the hydrologic cycle. Nature 419:228-232. https://doi.org/10.1038/nature01092

Allen RG, Pereira LS, Raes D, Smith M (1998) Crop evapotranspiration-Guidelines for computing crop water requirements, FAO Irrigation and Drainage Paper 56. FAO

Barradas VL (1991) Air temperature and humidity and human comfort index of some city parks of Mexico City. International Journal of Biometeorology 35:24-28. https://doi.org/10.1007/BF01040959

Betts AK, Ball JH, Beljaars ACM, Miller MJ, Viterbo PA (1996) The land surface-atmosphere interaction: A review based on observational and global modeling perspectives. Journal of Geophysical Research: Atmospheres 101:7209-7225. https://doi:10.1029/95jd02135

Boisier JP, De Noblet-Ducoudré N, Pitman AJ, Cruz FT, Delire C, Van den Hurk BJJM, Van der Molen MK, Müller C, Voldoire A (2012) Attributing the impacts of land-cover changes in temperate regions on surface temperature and heat fluxes to specific causes: Results from the 
first LUCID set of simulations. Journal of Geophysical Research: Atmospheres 117, D12116. https://doi:10.1029/2011jd017106

Bronstert A, Niehoff D, Bürger G (2002) Effects of climate and land-use change on storm runoff generation: present knowledge and modelling capabilities. Hydrological Processes 16:509-529. https://doi.org/10.1002/hyp.326

Boggs JL, Sun G (2011) Urbanization alters watershed hydrology in the Piedmont of North Carolina. Ecohydrology 4:256-264. https://doi:10.1002/eco.198

Clinton N, Gong P (2013) MODIS detected surface urban heat islands and sinks: Global locations and controls. Remote Sensing of Environment 134:294-304. https://doi:10.1016/j.rse.2013.03.008

Cuadrat JM, Vicente-Serrano S, Saz MA (2015) Influence of different factors on relative air humidity in Zaragoza, Spain. Frontiers in Earth Science 3, 10. https://doi:10.3389/feart.2015.00010

Dhara C (2020) Constraining Global Changes in Temperature and Precipitation From Observable Changes in Surface Radiative Heating. Geophysical Research Letters 47, e2020GL087576. https://doi:10.1029/2020g1087576

Ding Y, Liu Y (2013) Analysis of long-term variations of fog and haze in China in recent 50 years and their relations with atmospheric humidity. Science China Earth Sciences 57:36-46. https://doi:10.1007/s11430-013-4792-1

Du J, Wang K, Jiang S, Cui B, Wang J, Zhao C, Li J (2019) Urban Dry Island Effect Mitigated Urbanization Effect on Observed Warming in China. Journal of Climate 32:5705-5723. https://doi:10.1175/jcli-d-18-0712.1

Foley JA, Defries R, Asner GP, Barford C, Bonan G, Carpenter SR, Chapin FS, Coe MT, Daily GC, Gibbs HK, Helkowski JH, Holloway T, Howard EA, Kucharik CJ, Monfreda C, Patz JA, Prentice IC, Ramankutty N, Snyder PK (2005) Global consequences of land use. Science 309(5734):570-574. https://doi:10.1126/science.1111772

Fisher JB, Melton F, Middleton E, Hain C, Anderson M, Allen R, McCabe MF, Hook S, Baldocchi D, Townsend PA, Kilic A, Tu K, Miralles DD, Perret J, Lagouarde J-P, Waliser D, Purdy AJ, 

evapotranspiration: Global requirements for ecosystem functioning, carbon and climate feedbacks, agricultural management, and water resources. Water Resources Research 53:2618-2626. https://doi.org/10.1002/2016WR020175

Farrell K, Westlund H (2018) China's rapid urban ascent: an examination into the components of urban growth. Asian Geographer 35:85-106. https://doi:10.1080/10225706.2018.1476256

Gong P, Li X, Zhang W (2019) 40-Year (1978-2017) human settlement changes in China reflected by impervious surfaces from satellite remote sensing. Science Bulletin 64:756-763. https://doi:10.1016/j.scib.2019.04.024

Gaffen DJ, Ross RJ (1999) Climatology and Trends of U.S. Surface Humidity and Temperature. Journal of Climate 12:811-828. https://doi:10.1175/1520-0442(1999)012<0811:Catous $>2.0$. Co;2

Gultepe I, Tardif R, Michaelides SC, Cermak J, Bott A, Bendix J, Müller MD, Pagowski M, Hansen B, Ellrod G, Jacobs W, Toth G, Cober SG (2007) Fog Research: A Review of Past Achievements and Future Perspectives. Pure and Applied Geophysics 164:1121-1159. https://doi:10.1007/s00024-007-0211-x

Hage KD (1975) Urban-Rural Humidity Differences. Journal of Applied Meteorology 14:1277-1283. https://doi.org/10.1175/1520-0450(1975)014<1277:URHD>2.0.CO;2

Hondula DM, Balling RC, Jr. Andrade R, Scott Krayenhoff E, Middel A, Urban A, Georgescu M, Sailor DJ (2017) Biometeorology for cities. International Journal of Biometeorology 61:59-69. https://doi:10.1007/s00484-017-1412-3

Hao L, Huang X, Qin M, Liu Y, Li W, Sun G (2018) Ecohydrological Processes Explain Urban Dry Island Effects in a Wet Region, Southern China. Water Resources Research 54:6757-6771. https://doi:10.1029/2018wr023002

James NA, Matteson DS (2014) Ecp: An R package for nonparametric multiple change point analysis of multivariate data. Journal of Statistical Software 62:2-25.

577 Kendall MG (1975) Rank Correlation Methods, fourth ed. Charles Grifin, London

578 Lokoshchenko MA (2017) Urban Heat Island and Urban Dry Island in Moscow and Their 
579 Centennial Changes. Journal of Applied Meteorology and Climatology 56:2729-2745. $580 \quad$ https://doi:10.1175/jamc-d-16-0383.1

581 Liepert BG, Feichter J, Lohmann U, Roeckner E (2004) Can aerosols spin down the water cycle in 582

Luo M, Lau NC (2018) Increasing Heat Stress in Urban Areas of Eastern China: Acceleration by Urbanization. Geophysical Research Letters 45:13060-13069. https://doi.org/10.1029/2018GL080306

Luo M, Lau NC (2019) Urban Expansion and Drying Climate in an Urban Agglomeration of East China. Geophysical Research Letters 46:6868-6877. https://doi:10.1029/2019g1082736

Li D, Liao W, Rigden A, Liu X, Wang D, Malyshev S, Shevliakova E (2019) Urban heat island: 590 Aerodynamics or imperviousness? Science Advances 5, eaau4299. https://doi:10.1126/sciadv.aau4299

Landsberg HE, Maisel TN (1972) Micrometeorological observations in an area of urban growth. Boundary-Layer Meteorology 2:365-370. https://doi.org/10.1007/BF02184776

Li C, Sun G, Caldwell PV, Cohen E, Fang Y, Zhang Y, Oudin L, Sanchez GM, Meentemeyer RK (2020) Impacts of Urbanization on Watershed Water Balances Across the Conterminous United States. Water Resources Research 56, e2019WR026574. https://doi:10.1029/2019wr026574

Logan TM, Zaitchik B, Guikema S, Nisbet A (2020) Night and day: The influence and relative importance of urban characteristics on remotely sensed land surface temperature. Remote Sensing of Environment 247, 111861. https://doi:10.1016/j.rse.2020.111861

Li G, Zhang F, Jing Y, Liu Y, Sun G (2017) Response of evapotranspiration to changes in land use and land cover and climate in China during 2001-2013. Science of the Total Environment 596-597, 256-265. https://doi.org/10.1016/j.scitotenv.2017.04.080

Mann HB (1945) Nonparametric Tests against Trend. Econometrica: Journal of Economic and Social 13:245-259. https://doi.org/10.2307/1907187

Matheron G (1963) Principles of Geostatistics. Economic Geology 58:1246-1266. https://dx.doi.org/10.2113/gsecongeo.58.8.1246 
Matteson DS, James NA (2014) A Nonparametric Approach for Multiple Change Point Analysis of Multivariate Data. Journal of the American Statistical Association 109(505):334-345. https://doi.org/10.1080/01621459.2013.849605

Myneni R, Knyazikhin Y, Park T (2015) MOD15A2H MODIS/Terra Leaf Area Index/FPAR 8-Day L4 Global 500m SIN Grid V006. NASA EOSDIS Land Processes DAAC. https://doi.org/10.5067/MODIS/MOD15A2H.006

Ma H, Li T, Jiang Z, Gu P (2018) Unexpected large-scale atmospheric response to urbanization in East China. Climate Dynamics 52:4293-4303. https://doi:10.1007/s00382-018-4380-3

Miller RL, Tegen I, Perlwitz J (2004) Surface radiative forcing by soil dust aerosols and the hydrologic cycle. Journal of Geophysical Research: Atmospheres 109, D04203.

Moriwaki R, Watanabe K, Morimoto K (2013) Urban Dry Island Phenomenon and Its Imapct on Cloud Base Level. Journal of JSCE 1: 521-529. https://doi.org/10.2208/journalofjsce.1.1_521

Oke TR (1982) The energetic basis of the urban heat island. Quarterly Journal of the Royal Meteorological Society 108:1-24. https://doi.org/10.1002/qj.49710845502

Odongo VO, Van Oel PR, Van der Tol C, Su Z (2019) Impact of land use and land cover transitions and climate on evapotranspiration in the Lake Naivasha Basin, Kenya. Science of the Total Environment 682:19-30. https://doi.org/10.1016/j.scitotenv.2019.04.062

Pearson K (1895) Notes on Regression and Inheritance in the Case of Two Parents. Proceedings of the Royal Society of London 58:240-242. https://doi.org/10.1098/rspl.1895.0041

Pielke RA, Pitman A, Niyogi D, Mahmood R, McAlpine C, Hossain F, Goldewijk KK, Nair U, Betts R, Fall S, Reichstein M, Kabat P, De Noblet N (2011) Land use/land cover changes and climate: modeling analysis and observational evidence. Wiley Interdisciplinary Reviews: Climate Change 2:828-850. https://doi:10.1002/wcc.144

Rigden AJ, Li D (2017) Attribution of surface temperature anomalies induced by land use and land cover changes. Geophysical Research Letters 44:6814-6822. https://doi:10.1002/2017g1073811

Running S, Mu Q, Zhao M (2017) MOD16A2 MODIS/Terra Net Evapotranspiration 8-Day L4 Global 500m SIN Grid V006. NASA EOSDIS Land Processes DAAC. 
Sun G, Alstad K, Chen J, Chen S, Ford CR, Lin G, Liu C, Lu N, McNulty SG, Miao H, Noormets A, Vose JM, Wilske B, Zeppel M, Zhang Y, Zhang Z (2011) A general predictive model for estimating monthly ecosystem evapotranspiration. Ecohydrology 4:245-255.

640 https://doi.org/10.1002/eco.194

Song XP, Hansen MC, Stehman SV, Potapov PV, Tyukavina A, Vermote EF, Townshend JR (2018) Global land change from 1982 to 2016 . Nature 560:639-643. https://doi:10.1038/s41586-018-0411-9

Sun G, Lockaby BG (2012) Water quantity and quality at the urban-rural interface. In: Laband, D.N.; Lockaby, B.G.; Zipperer, W., eds. Urban-Rural Interfaces: Linking People and Nature. American Society of Agronomy, Crop Science Society of America, Soil Science Society of America. Madison, WI, pp 29-48

Song Y, Liu Y, Ding Y (2012) A study of surface humidity changes in China during the recent 50 years. Acta Meteorologica Sinica 26:541-553. https://doi:10.1007/s13351-012-0501-9

Sun Y, Zhang X, Ren G, Zwiers FW, Hu T (2016) Contribution of urbanization to warming in China. Nature Climate Change 6:706-709. https://doi.org/10.1038/nclimate2956

Taha H (1997) Urban Climates and Heat Islands: Albedo, Evapotranspiration, and Anthropogenic Heat. Energy and Buildings 25:99-103. https://doi.org/10.1016/S0378-7788(96)00999-1

Tan ML, Ibrahim AL, Yusop Z, Duan Z, Ling L (2015) Impacts of land-use and climate variability on hydrological components in the Johor River basin, Malaysia. Hydrological Sciences Journal 60(5):873-889. https://doi.org/10.1080/02626667.2014.967246

Wild M, Ohmura A, Gilgen H, Rosenfeld D (2004) On the consistency of trends in radiation and temperature records and implications for the global hydrological cycle. Geophysical Research Letters 31, L11201. https://doi:10.1029/2003g1019188

Yang P, Ren G, Hou W (2017) Temporal-Spatial Patterns of Relative Humidity and the Urban Dryness Island Effect in Beijing City. Journal of Applied Meteorology and Climatology 56:2221-2237. https://doi:10.1175/jamc-d-16-0338.1

Zhang CL, Chen F, Miao SG, Li QC, Xia XA, Xuan CY (2009) Impacts of urban expansion and 
663 future green planting on summer precipitation in the Beijing metropolitan area. Journal of 664 Geophysical Research 114, D02116. https://doi:10.1029/2008jd010328

665 Zhou D, Zhao S, Liu S, Zhang L, Zhu C (2014) Surface urban heat island in China's 32 major cities: 666 Spatial patterns and drivers. Remote Sensing of Environment 152:51-61. 667 https://doi:10.1016/j.rse.2014.05.017

668 Zhou D, Zhao S, Zhang L, Liu S (2016) Remotely sensed assessment of urbanization effects on 669 vegetation phenology in China's 32 major cities. Remote Sensing of Environment 176: 272-281. 670 https://doi.org/10.1016/j.rse.2016.02.010

671 


\section{Tables}

673 Table 1 Basic information of the study area

\begin{tabular}{cccc}
\hline & YRDUA & MUA & UUA \\
\hline Coverage & 26 cities & 31 cities & 16 cities \\
Core cities & Shanghai, Nanjing, & Wuhan, Nanchang, & Chengdu, Chongqing \\
Land area $\left(\mathrm{km}^{2}\right)$ & Hangzhou & Changsha & 185,000 \\
Population (million) & 211,700 & 317,000 & 91 \\
\hline
\end{tabular}

674

675 
676 Table 2 Linear trends of humidity indicators in core cities and the surrounding areas in the YREB

677 during 1965-2017 (the bold numbers indicating significant trends with $p<0.1$; RH: relative

678 humidity, $q$ : specific humidity, $e_{a}$ : actual vapor pressure, VPD: vapor pressure deficit)

\begin{tabular}{|c|c|c|c|c|}
\hline & RH (\% per decade) & $q(\mathrm{~g} / \mathrm{kg}$ per decade $)$ & $e_{a}(\mathrm{hPa}$ per decade $)$ & VPD (hPa per decade) \\
\hline Nanjing & -1.3592 & -0.0164 & -0.0329 & 0.4073 \\
\hline Shanghai & -2.1950 & -0.0358 & -0.0575 & 0.6960 \\
\hline Hangzhou & -1.8192 & -0.0158 & -0.0338 & 0.6201 \\
\hline Tongcheng & 0.0362 & 0.1167 & 0.1657 & 0.0386 \\
\hline Sheyang & -0.3989 & 0.1014 & 0.1640 & 0.1538 \\
\hline Chun'an & -0.3326 & 0.0773 & 0.1207 & 0.1222 \\
\hline Wuhan & -0.8042 & 0.0661 & 0.1056 & 0.3451 \\
\hline Nanchang & -1.1495 & 0.0046 & 0.0090 & 0.4051 \\
\hline Changsha & -0.4862 & 0.0939 & 0.1362 & 0.2116 \\
\hline Nanzhang & -0.2748 & 0.1011 & 0.1440 & 0.0558 \\
\hline Lushan & -0.2152 & 0.1404 & 0.1971 & 0.0618 \\
\hline Nanyue & 0.0313 & 0.1402 & 0.1950 & 0.0163 \\
\hline Chengdu & -1.4449 & -0.0370 & -0.0581 & 0.3827 \\
\hline Chongqing & -0.6609 & 0.0036 & 0.0074 & 0.2962 \\
\hline Nanbu & -0.2393 & 0.1110 & 0.1504 & 0.1658 \\
\hline Naxi & -0.1013 & 0.1186 & 0.1770 & 0.0953 \\
\hline
\end{tabular}

679

680 


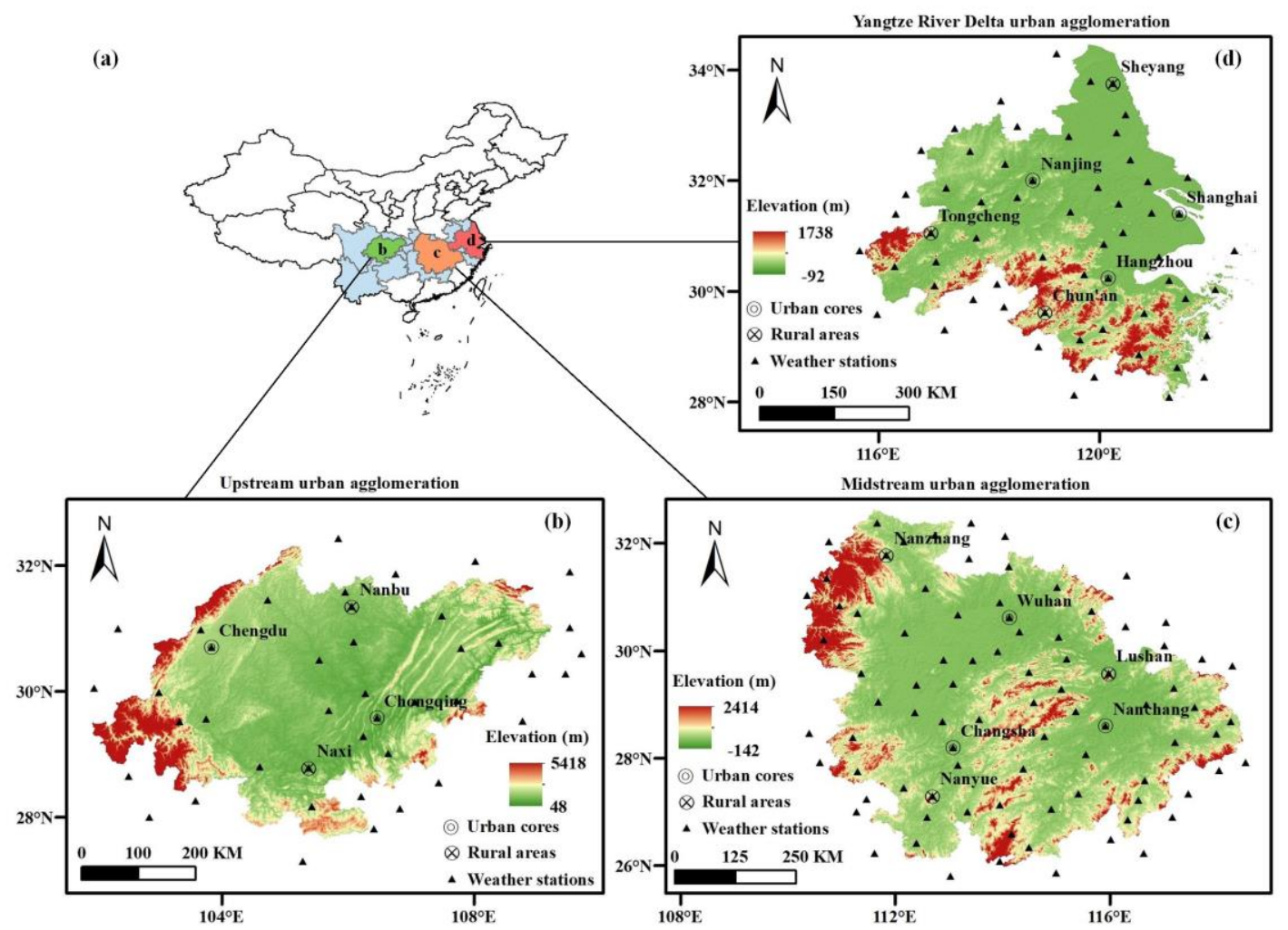

Fig. 1 Location and distribution of the weather stations, urban cores and rural areas of the study area: (a) the Yangtze River Economic Belt (YREB), (b) the upstream urban agglomeration (UUA), agglomeration (YRDUA) 

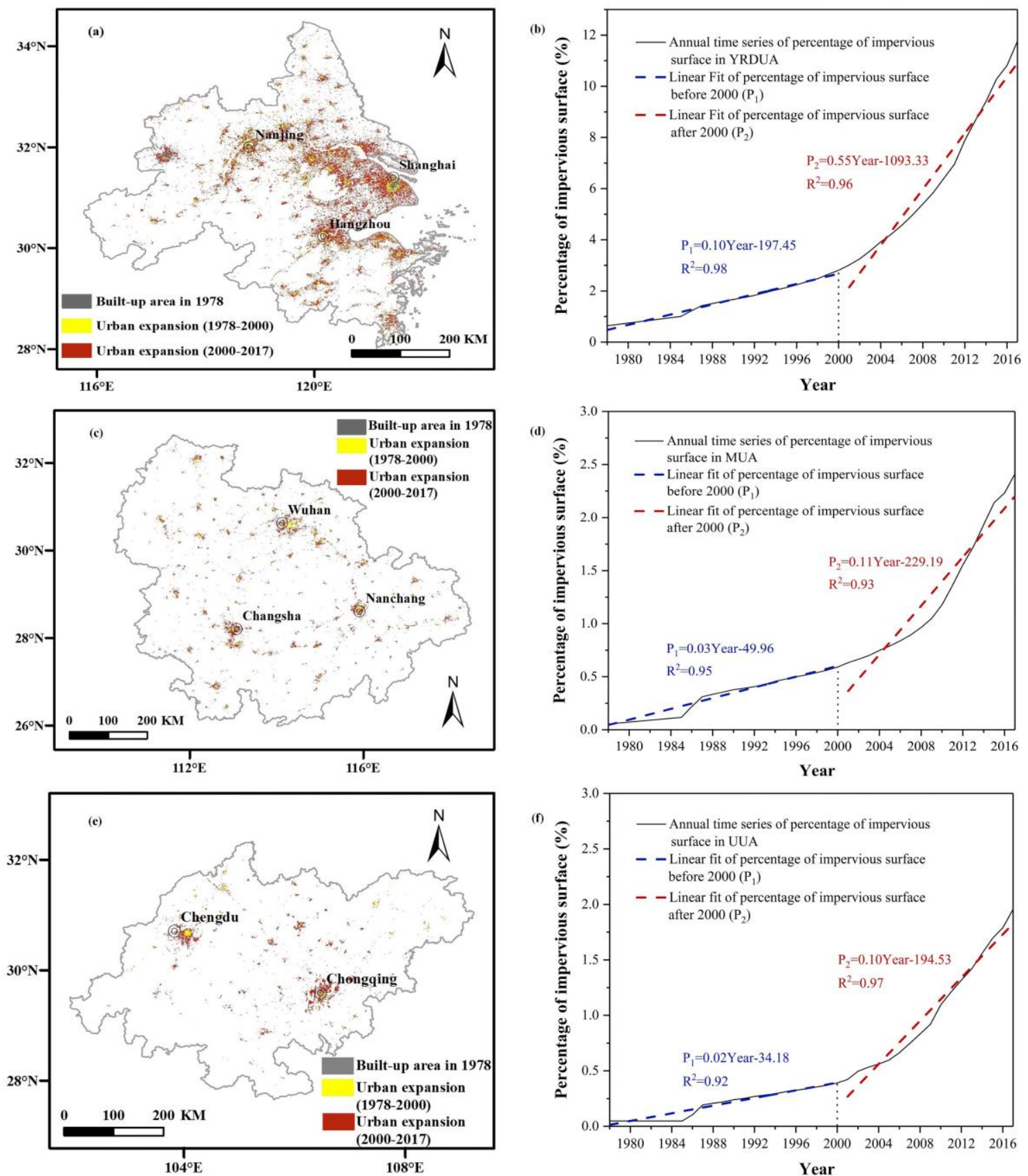

Fig. 2 Urban expansion processes of (a) the YRDUA, (c) the MUA and (e) the UUA from 1978 to

691 2017, and annual time series and linear fit of percentage of urban impervious surface of (b)

692 YRDUA, (d) MUA and (f) UUA 

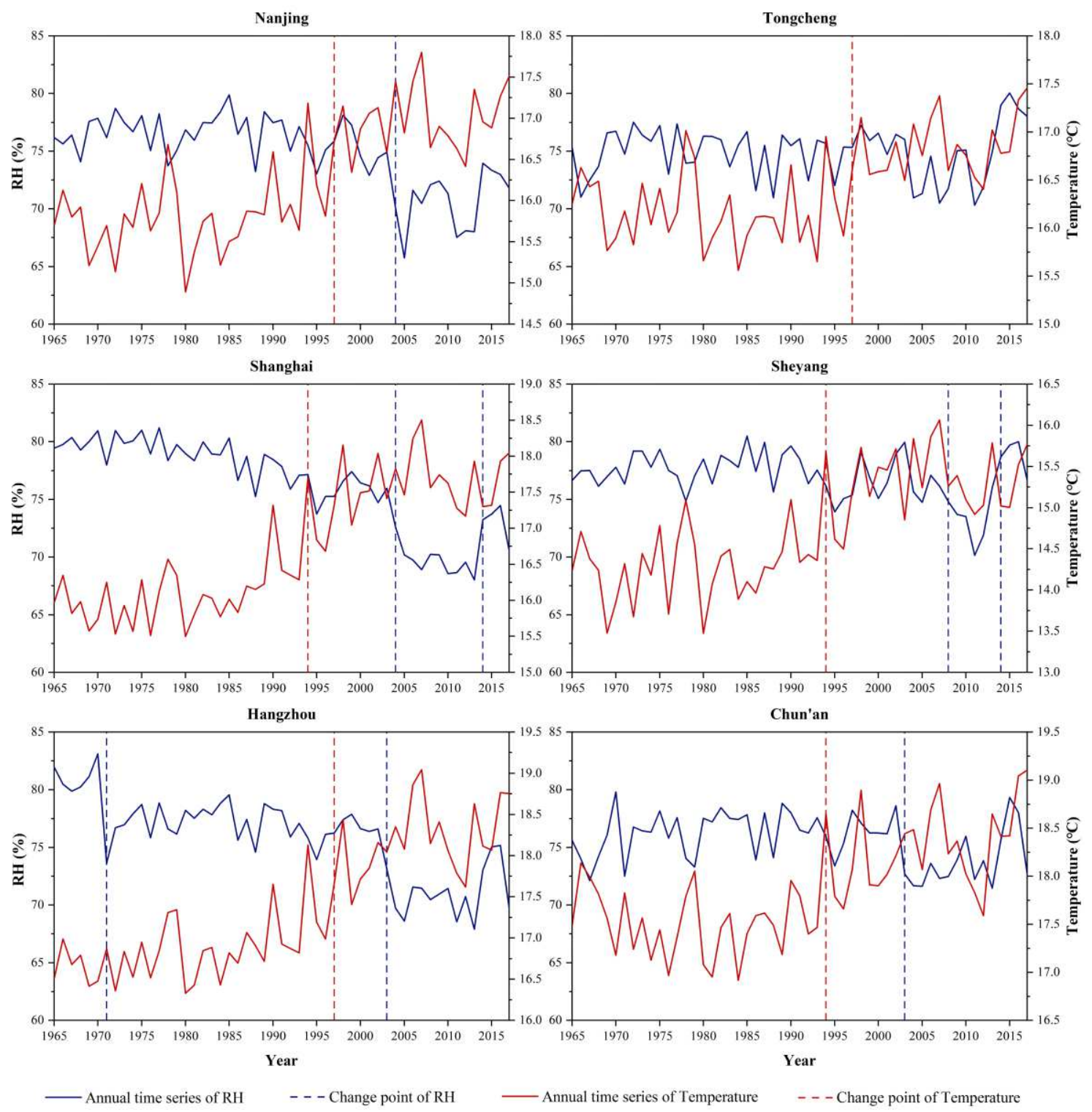

Fig. 3 Observed annual mean relative humidity (blue solid lines) and air temperature (red solid

lines) of core cities (double circles in Fig. 1d, left in Fig. 3) and rural areas (cross circles in Fig. 1d,

right in Fig. 3; 1965-2017) in the YRDUA (blue and red dashed lines indicating change points of

relative humidity and air temperature, respectively) 

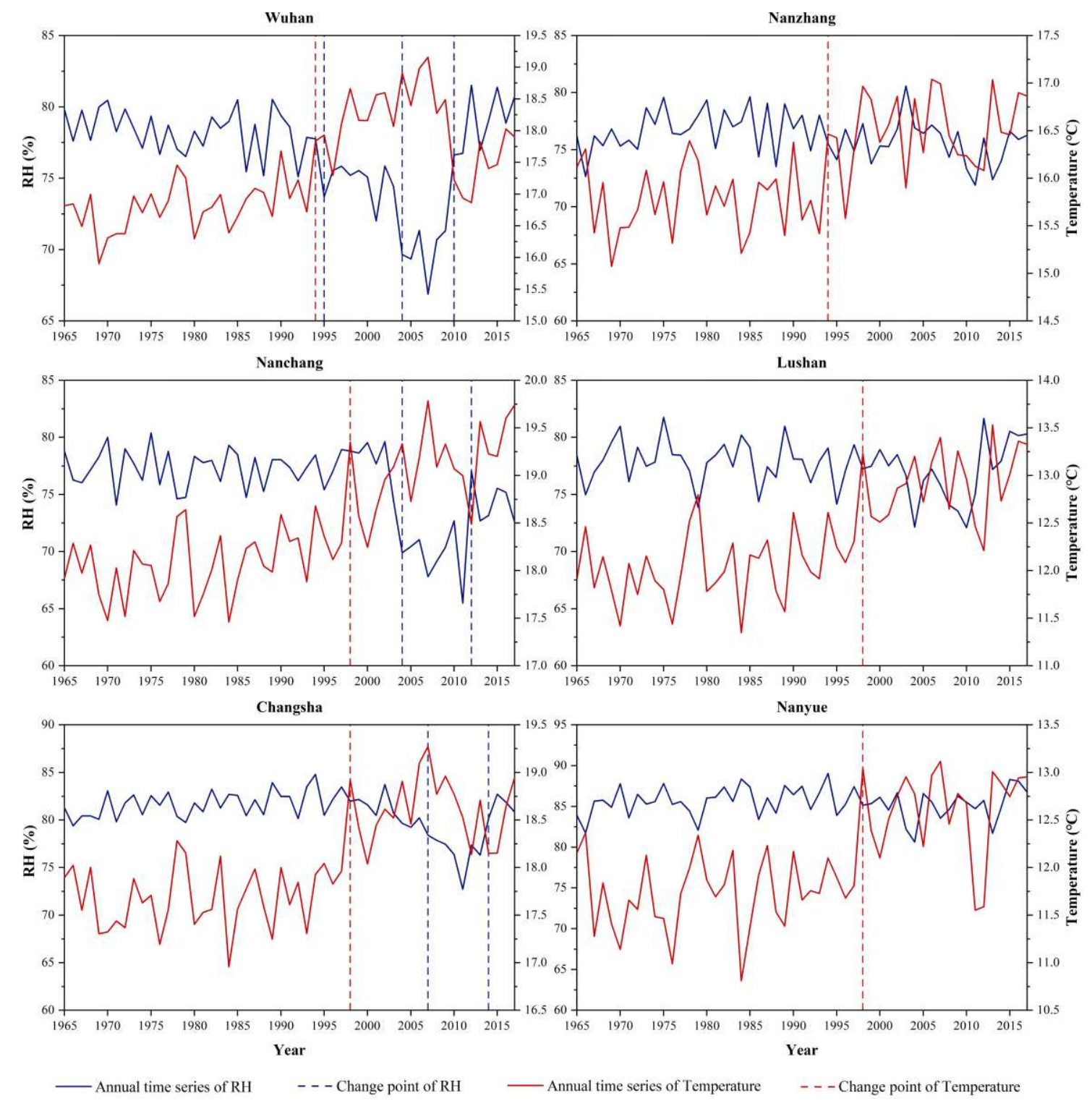

Fig. 4 Observed annual mean relative humidity (blue solid lines) and air temperature (red solid lines) of core cities (double circles in Fig. 1c, left in Fig. 4) and rural areas (cross circles in Fig. 1c, right in Fig. 4; 1965-2017) in the MUA (blue and red dashed lines indicate change points of relative humidity and air temperature, respectively) 

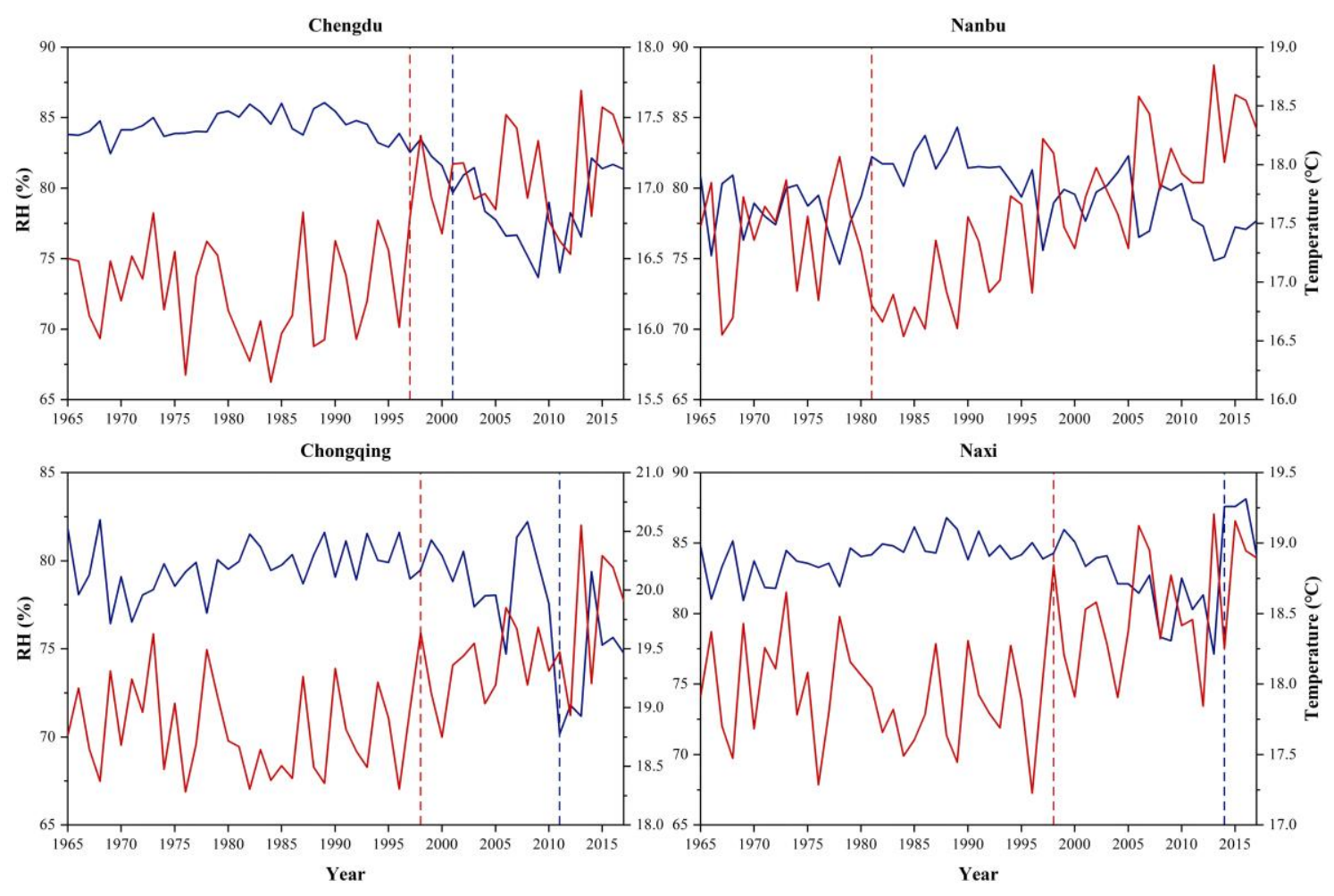

Fig. 5 Observed annual mean relative humidity (blue solid lines) and air temperature (red solid 

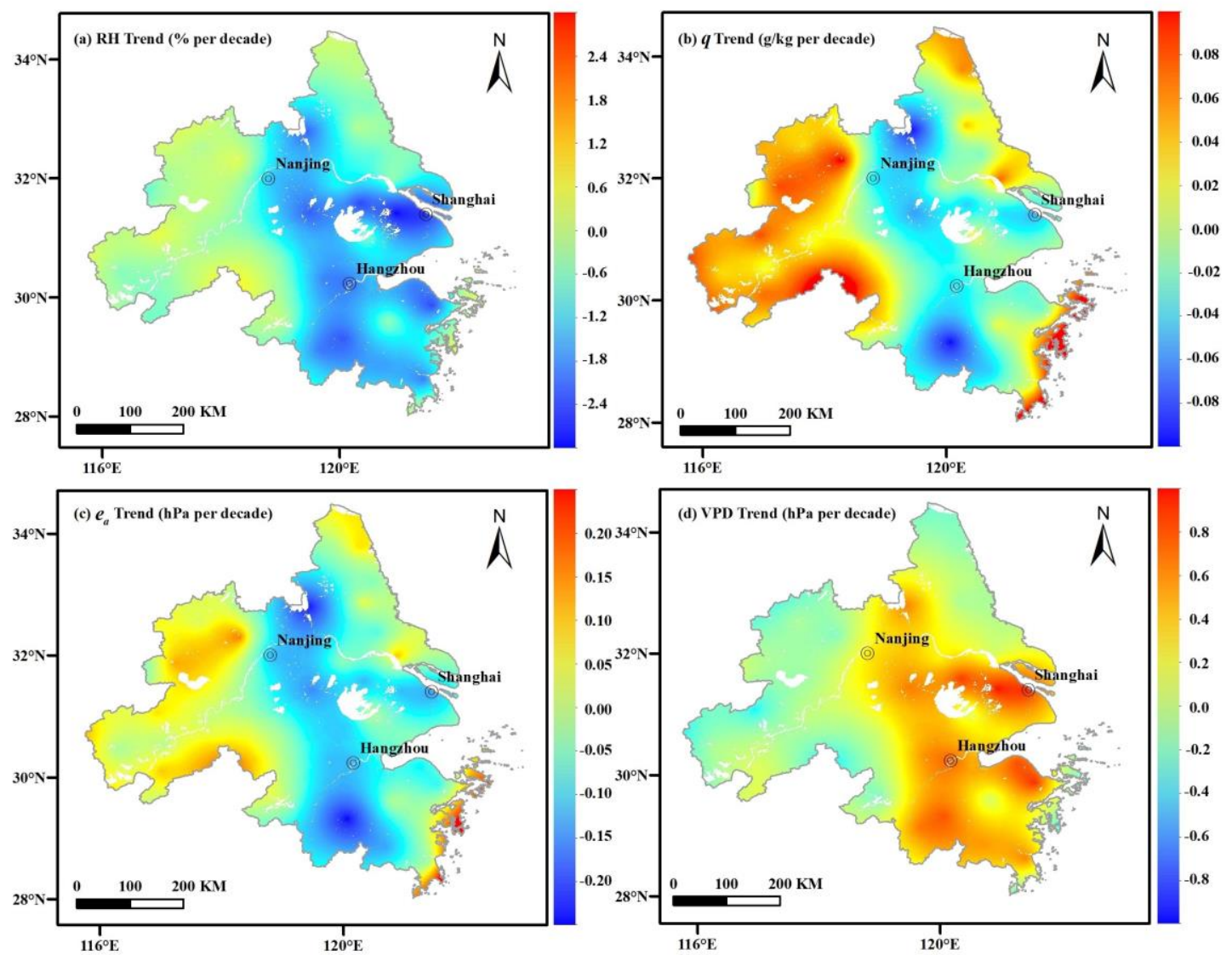

713 Fig. 6 Linear trends of annual mean (a) relative humidity ( $R H$ ), (b) specific humidity $(q)$, (c)

714 actual vapor pressure $\left(e_{a}\right)$ and (d) vapor pressure deficit (VPD) across the YRDUA (1965-2017) 

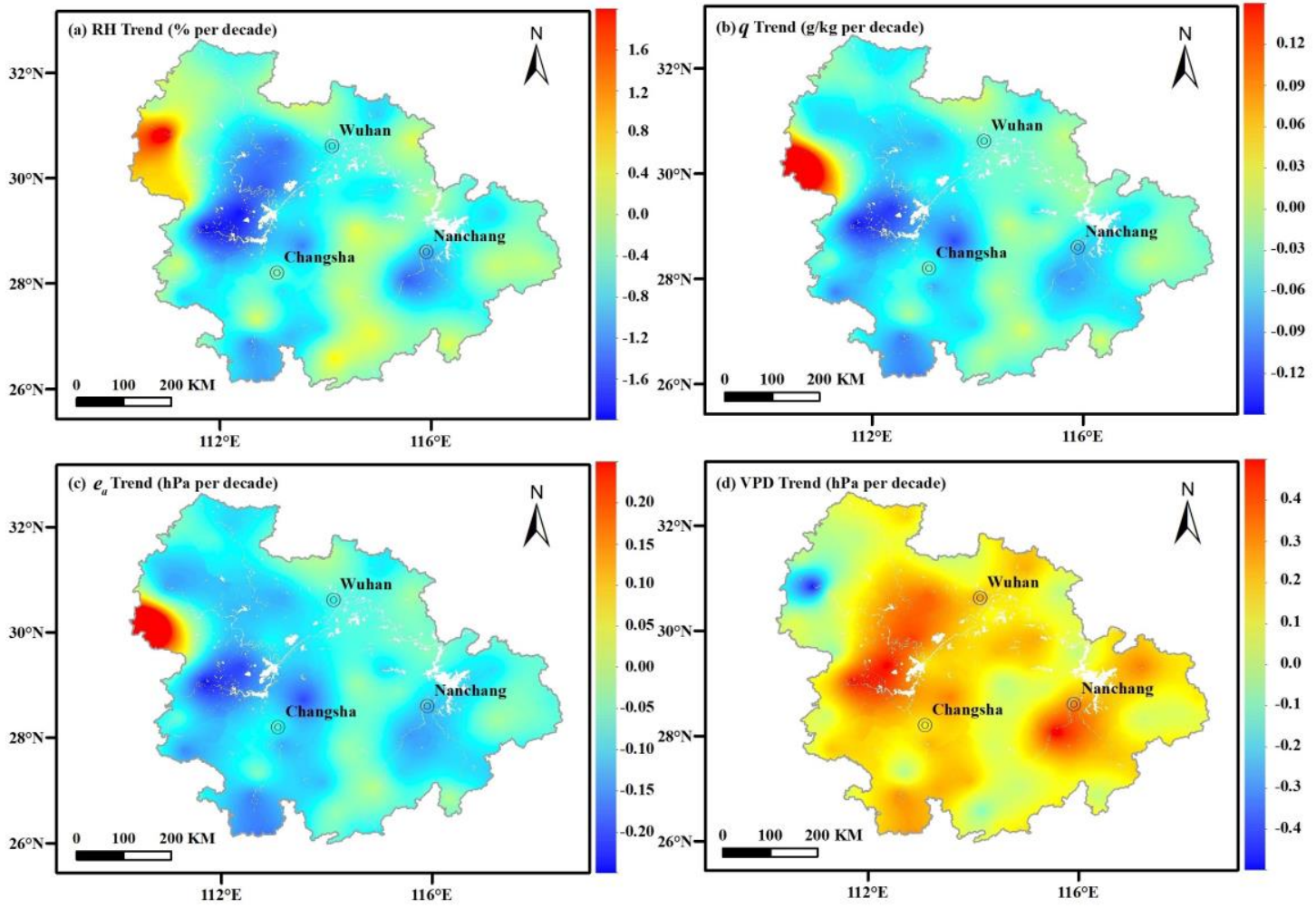

717 Fig. 7 Linear trends of annual mean (a) relative humidity $(R H)$, (b) specific humidity $(q)$, (c)

718 actual vapor pressure $\left(e_{a}\right)$ and (d) vapor pressure deficit (VPD) across the MUA (1965-2017) 

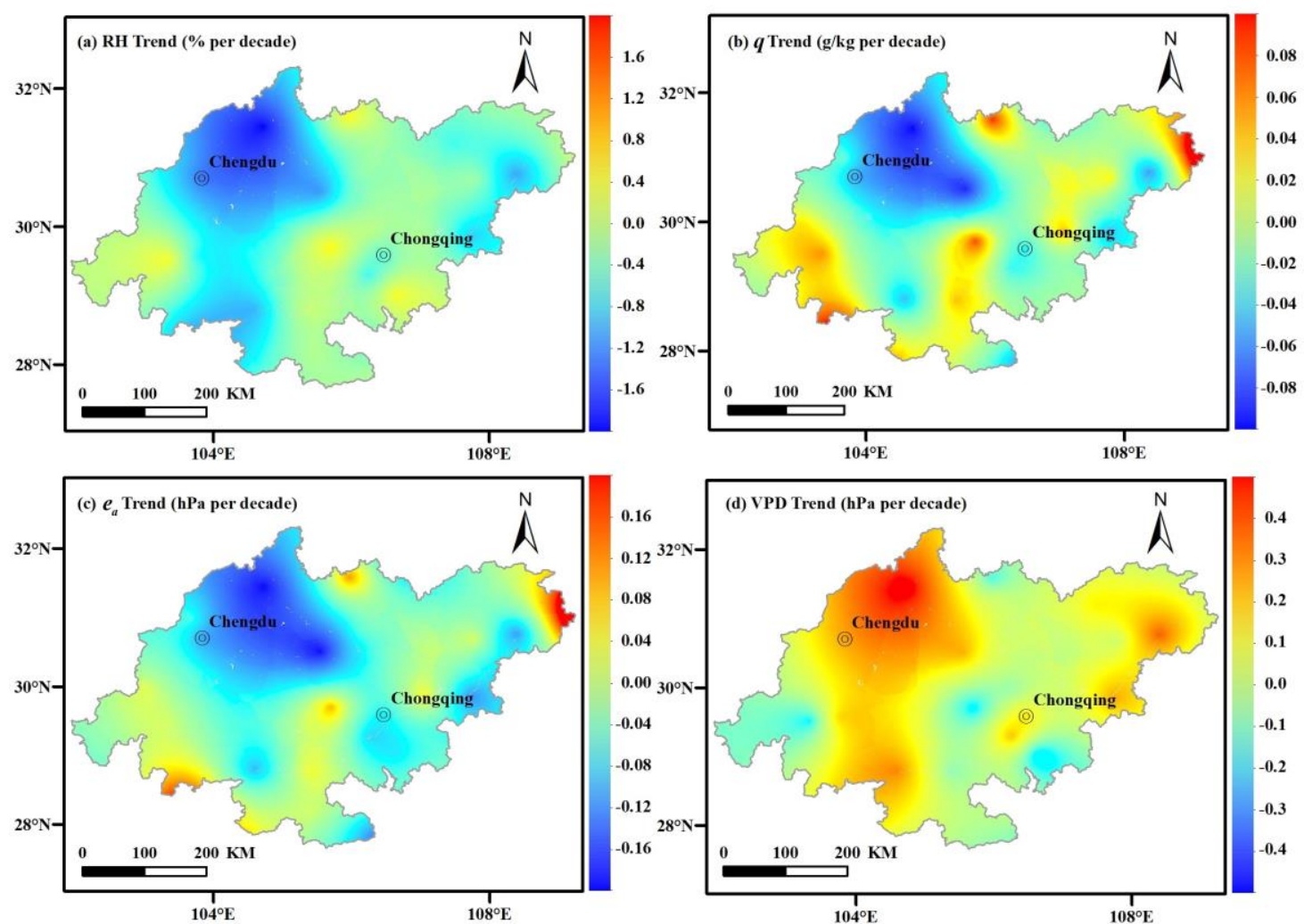

720

721 Fig. 8 Linear trends of annual mean (a) relative humidity ( $R H)$, (b) specific humidity $(q)$, (c)

722 actual vapor pressure $\left(e_{a}\right)$ and (d) vapor pressure deficit (VPD) across the UUA (1965-2017) 

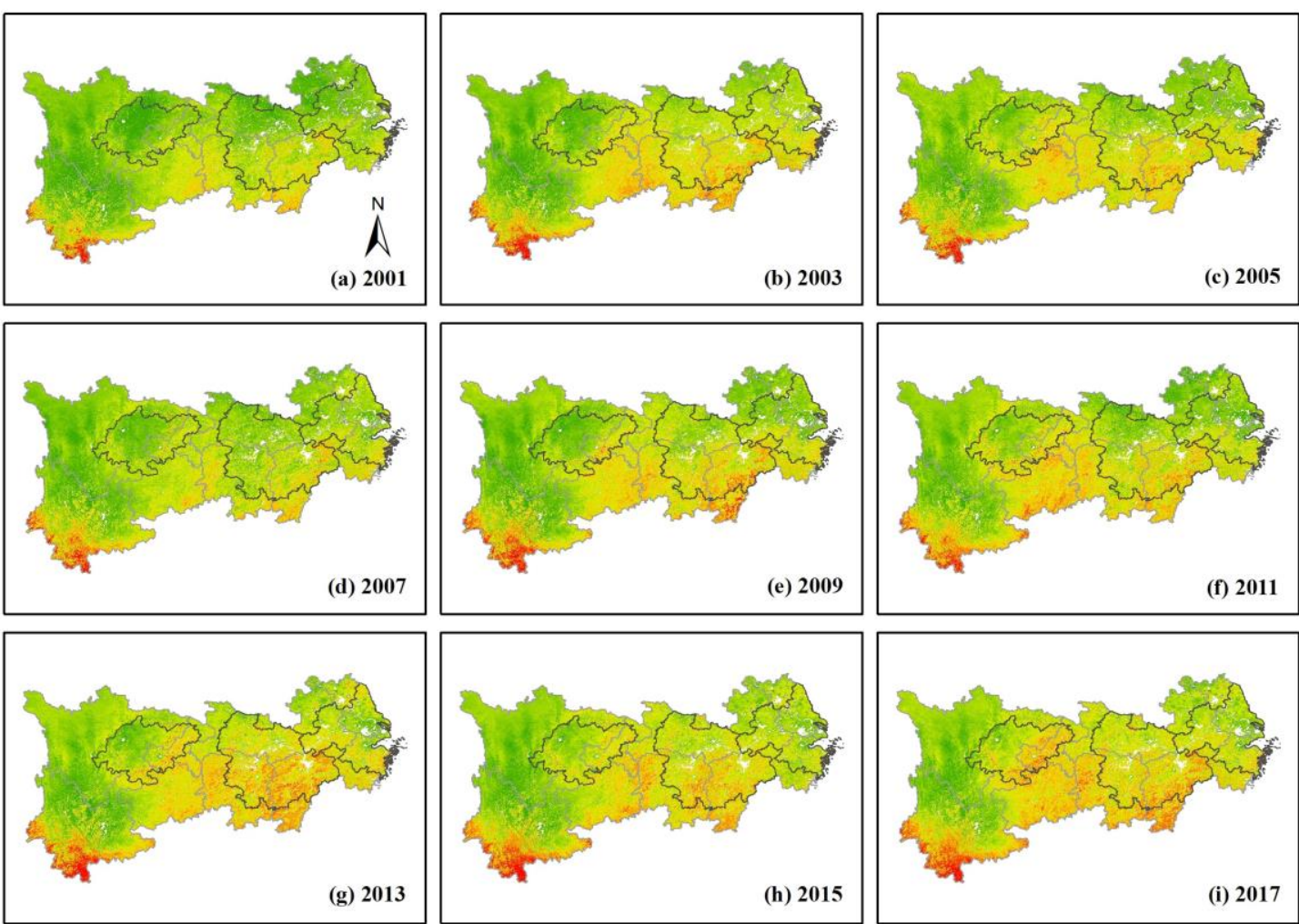

$0 \quad 500 \quad 1000 \mathrm{KM}$

ET
$(\mathrm{mm})$

$\begin{array}{llllllllll}200 & 400 & 600 & 800 & 1000 & 1200 & 1400 & 1600 & 1800 & 2000\end{array}$
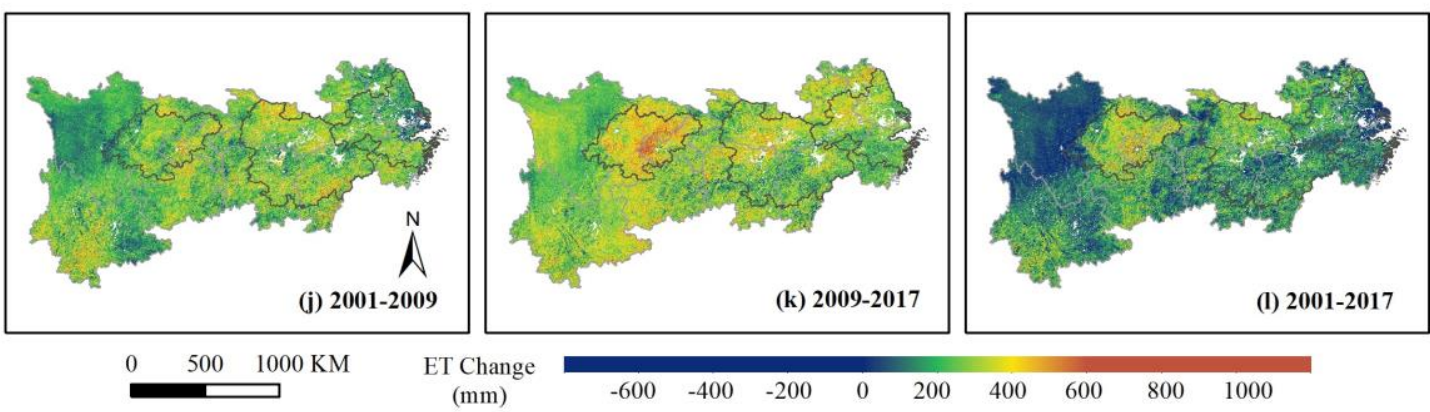

Fig. 9 Annual ET (a-i) and its changes (j-1) of the YREB from 2001 to 2017 (gray contours from the west to the east representing the UUA, the MUA and the YRDUA, respectively) 

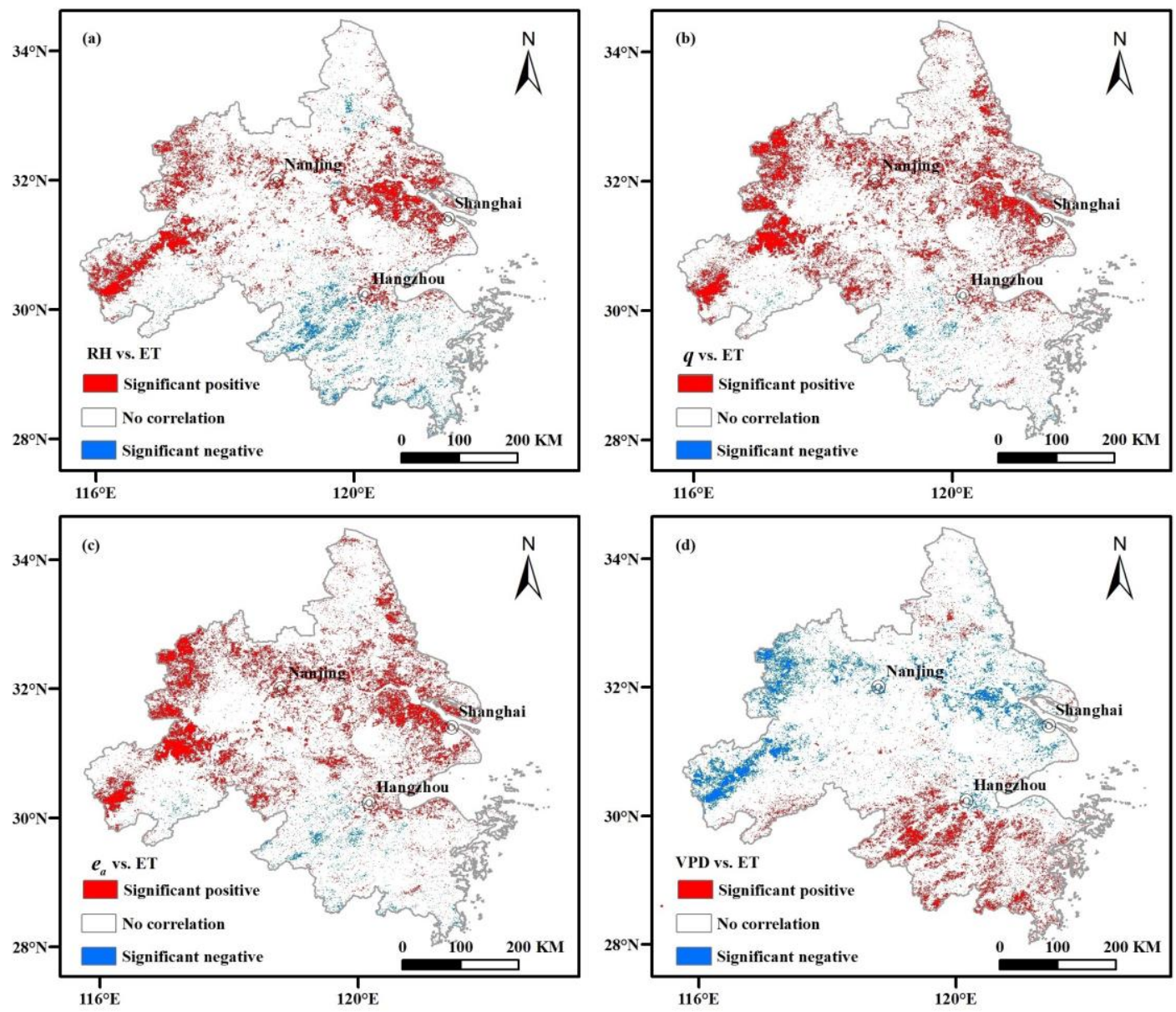

729 Fig. 10 Correlations of (a) $R H$ versus $E T$, (b) $q$ versus $E T$, (c) $e_{a}$ versus $E T$, and (d)

$730 V P D$ versus ET in the YRDUA (red and blue areas representing significant positive and 731 negative correlation with $p<0.1$, respectively, and the blank space representing no significant correlation; 2001-2017) 

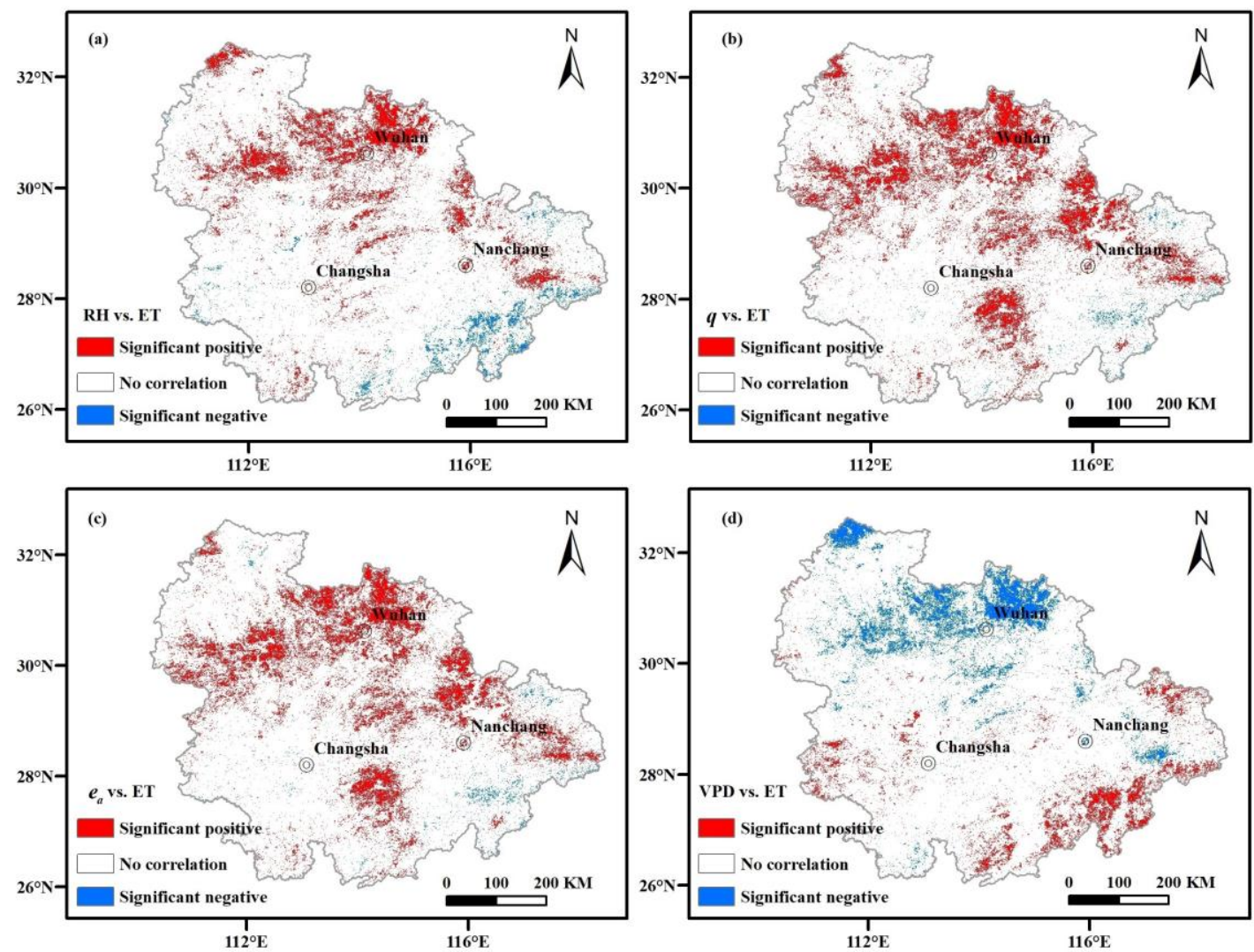

Fig. 11 Correlations of (a) $R H$ versus $E T$, (b) $q$ versus $E T$, (c) $e_{a}$ versus $E T$, and (d)

$736 V P D$ versus $E T$ in the MUA (red and blue areas representing significant positive and negative correlation with $p<0.1$, respectively, and the blank space representing no significant correlation; 2001-2017) 

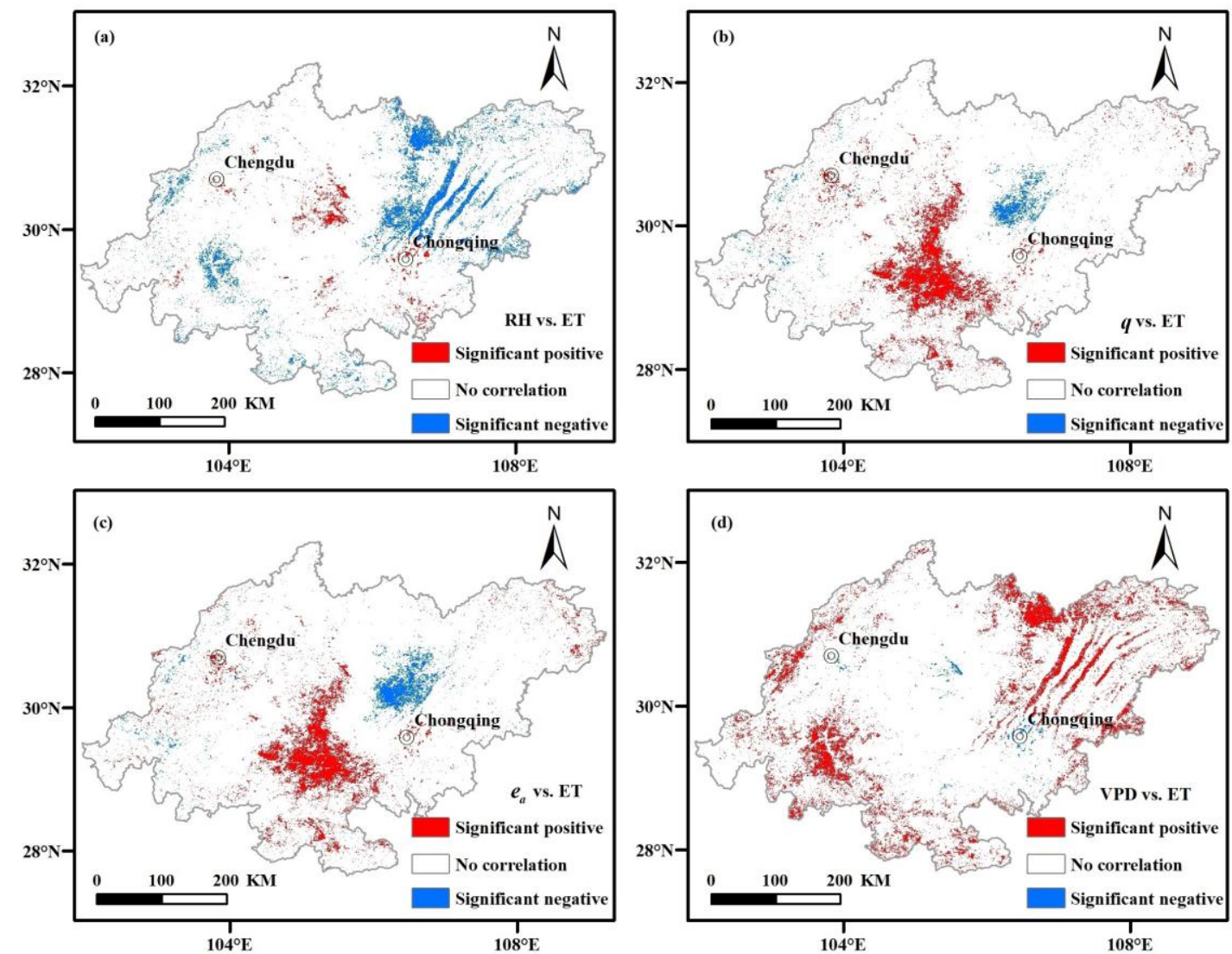

740

741 Fig. 12 Correlations of (a) $R H$ versus $E T$, (b) $q$ versus $E T$, (c) $e_{a}$ versus $E T$, and (d)

$742 V P D$ versus $E T$ in the UUA (red and blue areas representing significant positive and negative

743 correlation with $p<0.1$, respectively, and the blank space representing no significant correlation;

$744 \quad 2001-2017)$ 

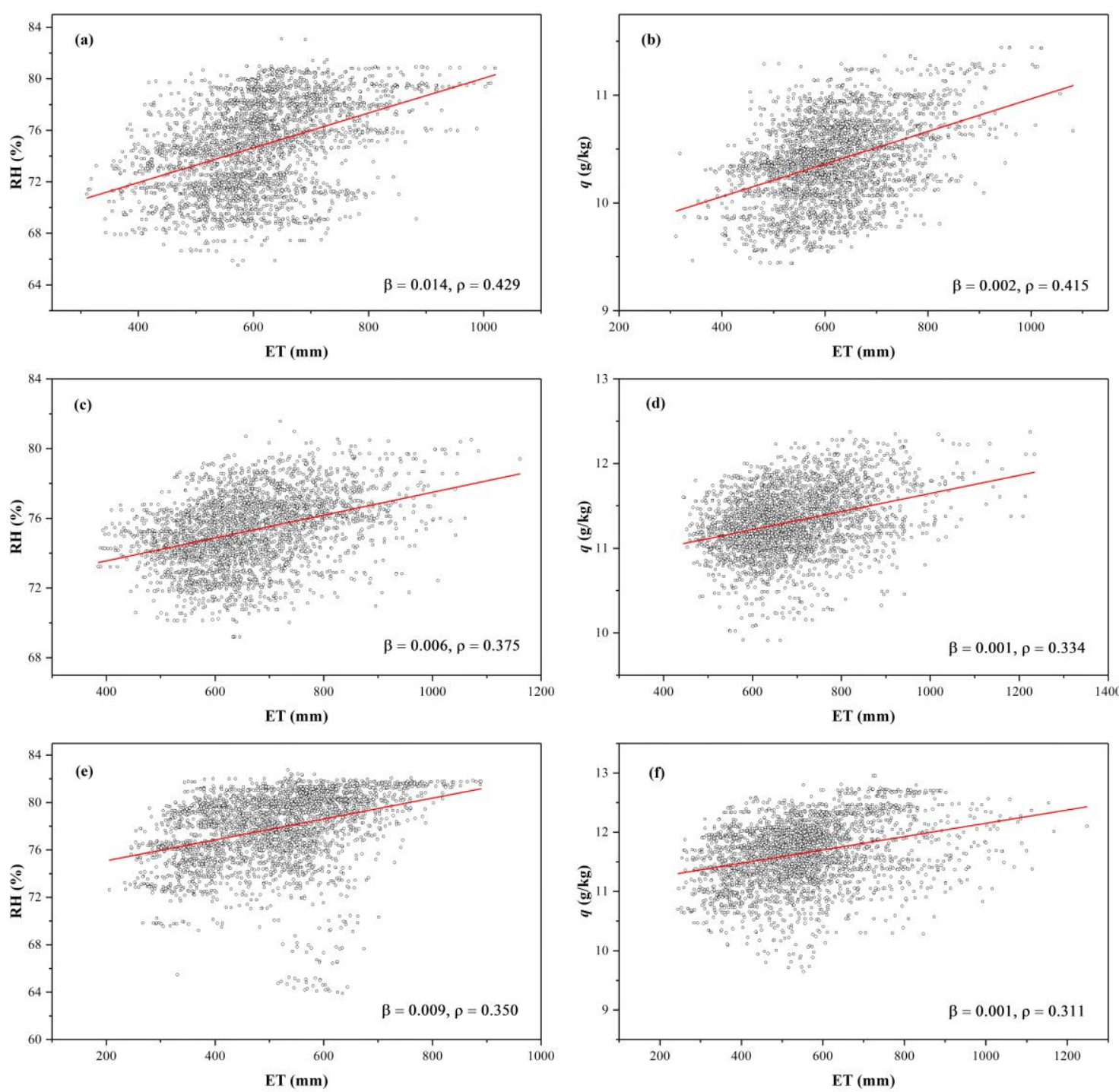

747 Fig. 13 Scatterplots of the humidity indicators versus ET of the significant positive correlation areas in (a-b) the YRDUA, (c-d) the MUA, and (e-f) the UUA ( $\beta$ denoting the slope of the fitted line; $\rho$ is the Pearson's correlation coefficient between the humidity indicator and ET, and all correlation coefficients are significant with $p<0.05$ ) 

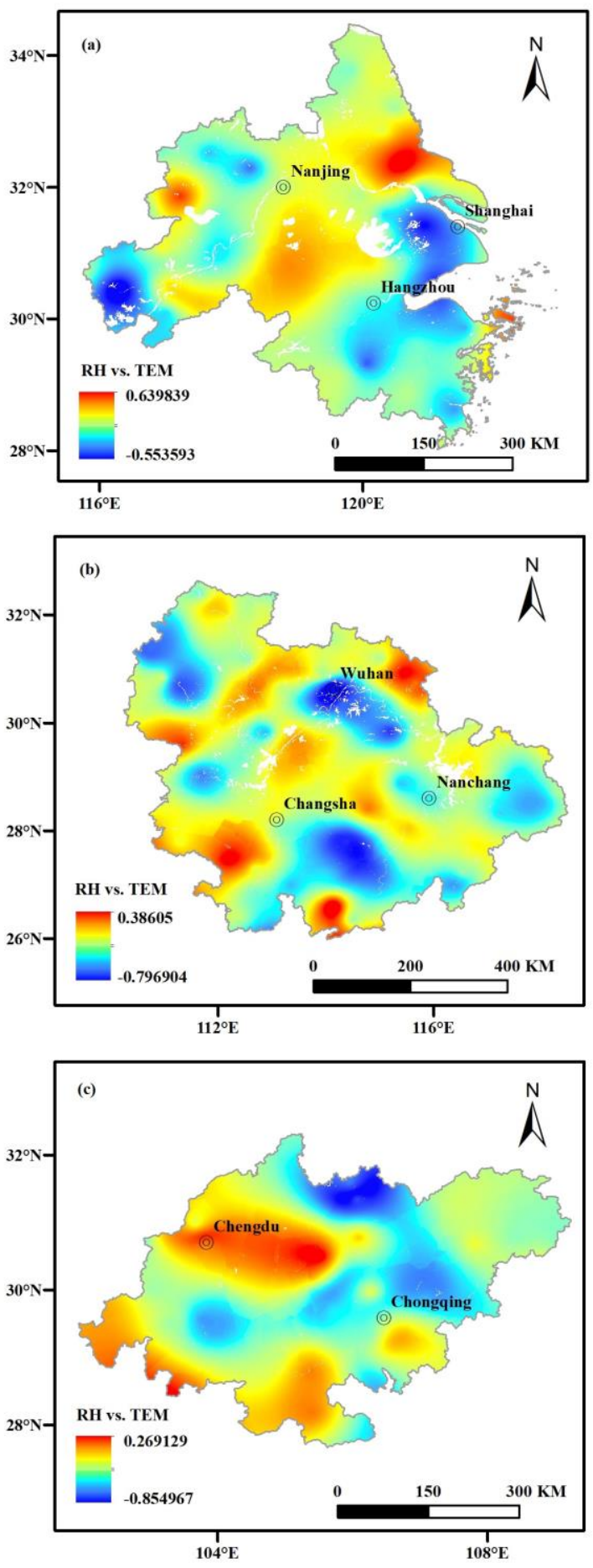

753 Fig. 14 Correlations of $R H$ versus air temperature (TEM) in (a) the YRDUA, (b) the MUA and 754 (c) the UUA (2001-2017) 

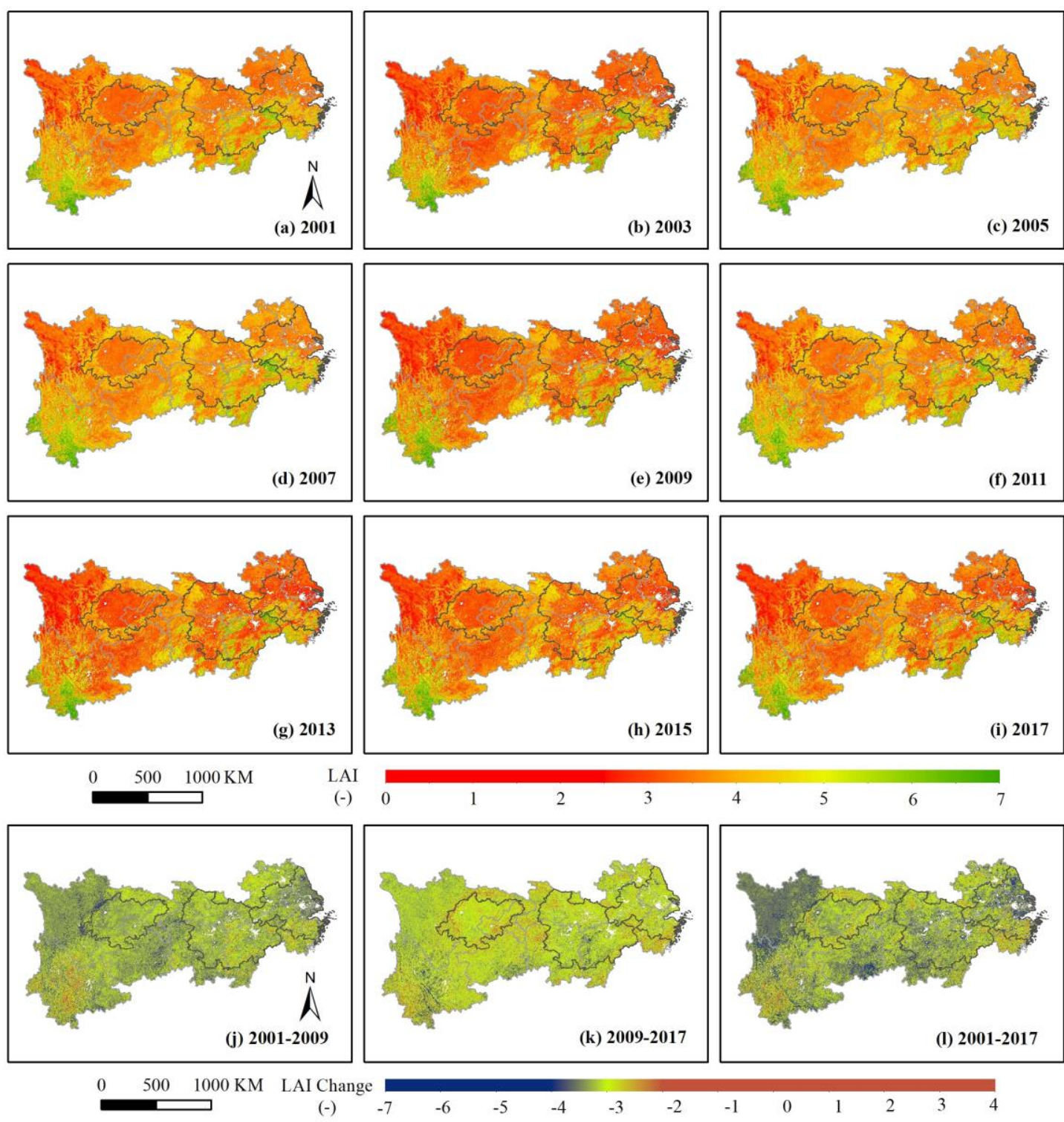

757

Fig. 15 Annual mean LAI (a-i) and its changes (j-1) in the YREB from 2001 to 2017 (gray

contours from the west to the east representing the UUA, the MUA and the YRDUA, respectively) 

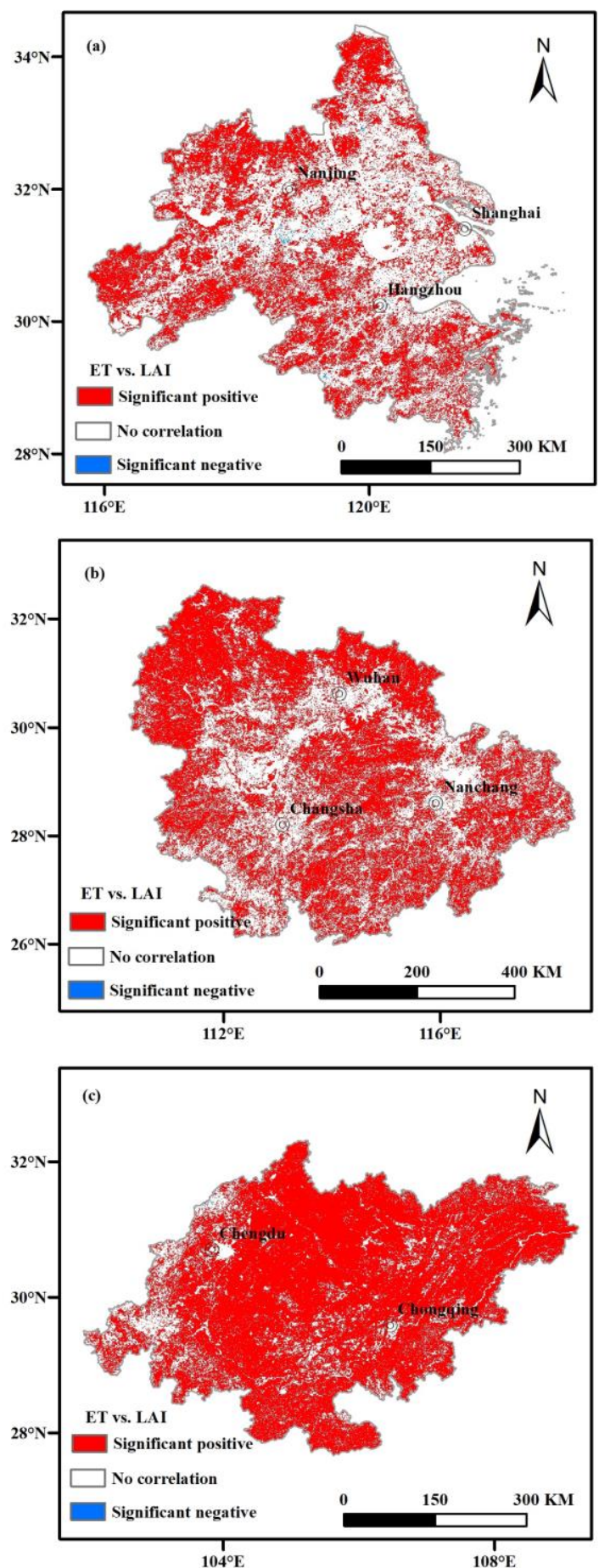

761 Fig. 16 Correlations of ET versus LAI in (a) the YRDUA, (b) the MUA and (c) the UUA (red 762 and blue areas representing significant positive and negative correlation with $p<0.1$, respectively,

763 and the blank space representing no significant correlation; 2001-2017) 